\title{
Minority Stress and Loneliness in a Global Sample of Sexual Minority Adults: The Roles of Social Anxiety, Social Inhibition, and Community Involvement
}

\author{
Eddy M. Elmer ${ }^{1}\left[\right.$ ] Theo van Tilburg $^{1}$ (I) $\cdot$ Tineke Fokkema $^{2,3}$ (D)
}

Received: 22 November 2020 / Revised: 29 June 2021 / Accepted: 12 August 2021 / Published online: 27 January 2022

(c) The Author(s) 2022

\begin{abstract}
Research suggests that loneliness among sexual minority adults is associated with marginalization, but it is unclear which processes may underlie this relationship. This cross-sectional study examined five possibilities: stigma preoccupation, internalized homonegativity, sexual orientation concealment, social anxiety, and social inhibition. The study also examined the possible protective role of LGBTQ community involvement. Respondents were 7856 sexual minority adults aged 18-88 years from 85 countries who completed an online survey. Results of structural equation modeling indicated that marginalization was positively associated with both social and emotional loneliness, and that part of this relationship was indirect via proximal minority stress factors (especially stigma preoccupation) and, in turn, social anxiety and social inhibition. Moreover, while LGBTQ community involvement was associated with greater marginalization, it was also associated with lower levels of proximal stress and both forms of loneliness. Among those who were more involved in the LGBTQ community, the associations between marginalization and proximal stress were somewhat weaker, as were those between stigma preoccupation and social anxiety, and between social inhibition and social loneliness. In contrast, the associations between concealment and social anxiety were somewhat stronger. Model fit and patterns of association were similar after controlling for the possible confounding effect of dispositional negative affectivity, but several coefficients were lower. Findings underscore the continuing need to counter marginalization of sexual minorities, both outside and within the LGBTQ community, and suggest possible avenues for alleviating loneliness at the individual level, such as cognitive-behavioral interventions targeting stigma preoccupation and social anxiety.
\end{abstract}

Keywords Sexual orientation $\cdot$ Lesbian/gay/bisexual $\cdot$ Stigma $\cdot$ Harassment $\cdot$ Discrimination

\section{Introduction}

Humans are a fundamentally social species with a basic need to belong and a strong drive for intimacy and companionship (Baumeister \& Leary, 1995; Cacioppo \& Patrick, 2008). As such, they are prone to loneliness-the painful emotional response resulting from a mismatch between actual and desired relationships (de Jong Gierveld, 1987). Loneliness can present

Eddy M. Elmer

eddy@eddyelmer.com

1 Department of Sociology, Vrije Universiteit Amsterdam, De Boelelaan 1105, 1081 HV Amsterdam, Netherlands

2 Netherlands Interdisciplinary Demographic Institute, KNAW/University of Groningen, The Hague, Netherlands

3 Department of Public Administration and Sociology, Erasmus University Rotterdam, Rotterdam, Netherlands in at least two forms: social and emotional (Hawkley et al., 2005; Weiss, 1973). Social loneliness is the perceived absence of a satisfactory social network - a broad circle of friends, family, colleagues, and neighbors who provide support and a sense of belonging, companionship, and community. Emotional loneliness, also known as intimate loneliness, is the perceived absence of a satisfying, meaningful relationship with a significant other-a close, secure attachment figure like a spouse or best friend who not only provides emotional support but also affirms our value as a person. Emotional loneliness can be accompanied by feelings of desolation or abandonment. Unlike isolation, loneliness is subjective: depending on one's unique needs for social connection and intimacy, and on how the quality of relationships is perceived, a person may feel lonely on their own, in a relationship, or in a group.

Like hunger, thirst, and physical pain, loneliness evolved to alert us when our basic needs are lacking and prompts us to take corrective action (Cacioppo \& Patrick, 2008; Cacioppo 
et al., 2013). Although beneficial in terms of motivating social connection, unresolved loneliness is a risk factor for morbidity and early mortality (Cacioppo \& Cacioppo, 2014; Holt-Lunstad et al., 2015). Consequently, it is an emerging public health issue drawing attention from governments around the world (e.g., Elmer, 2018; Kodama, 2021; National Seniors Council of Canada, 2017; United Kingdom Government, 2018).

Risk factors for loneliness are diverse and include a small social network (if a larger one is desired), poor-quality relationships, attachment insecurity, unrealistic expectations, personality traits like negative affectivity and neuroticism, mental health issues, disability, and genetics (de Jong Gierveld et al., 2018; Elmer, 2018; Lim et al., 2020). Loneliness can become self-reinforcing by increasing social withdrawal; passivity; hypervigilance for social threat and conflict; negative interpretation of neutral or ambiguous social cues; unfavorable appraisals of self and others; hostility; and other negative emotions and behaviours (Cacioppo \& Hawkley, 2009; Cacioppo et al., 2017; Mund \& Johnson, 2021; Mund \& Neyer, 2016, 2019; Qualter et al., 2015; Segel-Karpas \& Ayalon, 2020; Spithoven et al., 2017; van Winkel et al., 2017). These dynamics can elicit negative perceptions and reactions by others and make them feel lonely, too (Lieberz et al., 2021; Simon \& Walker, 2018). In this way, loneliness can spread within social networks (Cacioppo et al., 2009).

\section{Loneliness and Sexual Orientation}

Belonging to a sexual minority is a risk factor for loneliness that has received less attention in the research literature than the popular press (e.g., Bereznai, 2006; Blum, 2018; Dodwell, 2017; Hobbes, 2017). Of the few existing studies, most have focused on midlife and older adults in specific countries. Dutch researchers have found that older lesbian, gay, and bisexual (LGB) adults in the Netherlands are lonelier than their heterosexual peers (Fokkema \& Kuyper, 2009; van Lisdonk \& Kuyper, 2015). Others have found that midlife and older LGB adults in North America are more likely to feel lonely and fear growing old and dying alone (AARP Foundation, 2018; Angus Reid Institute, 2019; Hsieh \& Liu, 2021; MetLife, 2010; SAGE USA, 2014). Doyle and Molix (2016) found a similar sexual orientation disparity in a mixed-age sample, as did Eres et al. (2021), but their results were based on American and Australian samples, respectively. The current study extends this small literature by examining loneliness among sexual minority adults across a wider range of ages and countries.

\section{Loneliness and Minority Stress}

The sexual orientation disparity in loneliness may be due in part to sociodemographic differences. Sexual minorities are more likely to be single, childless, living alone, in less frequent contact with families of origin, and generally at greater risk for isolation (Angus Reid Institute, 2019; Eres et al., 2021; European Union Agency for Fundamental Rights, 2014; Fokkema \& Kuyper, 2009; Hsieh \& Liu, 2021; Lunn et al., 2017; MetLife, 2010; SAGE USA, 2014).

An equally important reason may be minority stress: the negative impact of living with a stigmatized identity (Meyer, 1995, 2003). There are two types of minority stress. Distal stressors are prejudicial experiences like discrimination, harassment, and violence. Proximal stressors are internal, subjective reactions to distal stressors. One common proximal stressor is concealment - the desire to hide one's sexual orientation from others. Another proximal stressor is internalized homonegativity, also known as self-stigma, which is the internalization of negative societal attitudes toward nonheterosexual orientations. Sexual minorities who internalize these attitudes—even if they are subtle and implicit—can subsequently develop feelings of guilt, inferiority, and shame. A third proximal stressor is sexual orientation rejection sensitivity - the tendency to anxiously or angrily expect, readily perceive, and intensely react to rejection based on one's sexuality (Feinstein, 2020; Pachankis et al., 2008). This enduring disposition, rooted in early experiences of rejection, may begin as a form of self-protection but become maladaptive when it is activated indiscriminately and in situations that are likely benign (Feinstein, 2020). According to minority stress theory, both distal and proximal stressors help explain why sexual minorities are at increased risk for problems like anxiety and depression (Meyer, 1995, 2003).

Minority stress may be particularly relevant to loneliness. Discrimination and harassment can increase proximal stressors that interfere with the formation and maintenance of satisfying relationships. Those who desire to conceal their sexual orientation to avoid negative reactions may self-isolate and have difficulty finding other sexual minority friends or partners. They may be guarded and reluctant to discuss their personal lives, resulting in superficial, distant interactions that undermine intimacy and connection (Newheiser $\&$ Barreto, 2014). Concealment may prevent couples from engaging in shared activities in public, and the constant fear of discovery may create stress that ultimately impacts relationship quality (Knoble \& Linville, 2010; Pepping et al., 2019). Sexual minorities who anxiously or angrily expect rejection, and readily perceive it even in the presence of minimal or ambiguous cues, may become avoidant, aloof, hostile, or rejecting - defensive behavior that drives people away (Feinstein, 2020; London et al., 2007; Norona \& Welsh, 2016; Watson \& Nesdale, 2012; Zimmer-Gembeck et al., 2016). Internalized beliefs that non-heterosexual relationships are inferior or dysfunctional could motivate relationship avoidance; reduce trust, commitment, and intimacy; and increase relationship conflict and dissatisfaction (Cao et al., 2017; Downs, 2012; Doyle \& Molix, 2015; Frost \& Meyer, 2009). Such beliefs could also lead to unrealistically high 
relationship standards-an over-compensation that narrows one's pool of potential friends and partners, and strains existing relationships (Downs, 2012). Holding negative views of one's sexual orientation can also make one less attractive as a potential friend or relationship partner (Frost \& Meyer, 2009). Even absent proximal stress, marginalization could increase loneliness by making one feel different, misunderstood, or estranged from others. Minority stress might also be exacerbated by loneliness itself, as the latter can increase hypervigilance for social threat and conflict; negative appraisal of others; and social withdrawal (Cacioppo \& Hawkley, 2009; Qualter et al., 2015; Segel-Karpas \& Ayalon, 2020; Spithoven et al., 2017; van Winkel et al., 2017). Thus, minority stress and loneliness may be mutually reinforcing.

These dynamics may explain some of the empirical findings linking sexual minority stress with loneliness. Mereish and Poteat (2015) found that loneliness is associated with marginalization, internalized homonegativity, and concealment among sexual minority adults in the USA. Similar results were found in a more global sample (Mereish et al., 2017). In a study of Chinese gay men, disclosure of sexual orientation was associated with lower levels of loneliness (Jiang et al., 2019). In American studies of midlife and older sexual minorities, loneliness was associated with internalized homonegativity (Jacobs \& Kane, 2012; Kim \& FredriksenGoldsen, 2016). In two Dutch samples, older LGB adults who experienced rejection (or anticipated experiencing it) tended to be lonelier, and minority stress accounted for variance in loneliness over and above partner status, social network size, health, and self-esteem (Kuyper \& Fokkema, 2010; van Lisdonk \& Kuyper, 2015). Finally, a prospective study of midlife and older LGB adults in the UK found that perceived discrimination predicted loneliness six months later (Jackson et al., 2019). In the current study, we sought to extend these findings to a larger, international sample.

While past studies have focused on overt marginalization like discrimination, verbal harassment, and violence, fewer have examined less overt forms like microaggressions—-subtle, seemingly innocuous, and often ambiguous words or behaviors that, intentional or not, may convey bias, disrespect, or hostility toward marginalized groups (Lilienfeld, 2017; Nadal et al., 2016). Although more subtle, these forms of marginalization may affect self-esteem and mood (Dyar et al., 2020; Wegner \& Wright, 2016; Wright \& Wegner, 2012). It is unknown if they are also associated with loneliness. Accordingly, our study examines both overt marginalization and microaggressions, providing a more comprehensive assessment of distal minority stress. Use of a less comprehensive measure may partly explain why one study failed to find a link between marginalization and loneliness (Doyle \& Molix, 2016).

We also examined sexual orientation stigma preoccupation, a less commonly examined proximal stress factor. This is the maladaptive hyper-awareness of the stigmatization of one's sexual orientation (Dyar et al., 2018). Stigma preoccupation is considered the cognitive-affective consequence of rejection sensitivity: those who are rejection-sensitive may become preoccupied and overly worried about how others perceive and judge them based on their sexual orientation (Dyar et al., 2018). Research has found that both rejection sensitivity and stigma preoccupation play a role in the association between marginalization and anxiety, including social anxiety (Dyar et al., 2018; Feinstein et al., 2012; Timmins et al., 2020). Stigma preoccupation may also be associated with loneliness, perhaps by increasing self-consciousness and self-focus - traits that can be unattractive to others (Cacioppo et al., 2017). This would be in line with prospective studies finding that rejection sensitivity predicts both social anxiety and loneliness in the general population (London et al., 2007; Zhou et al., 2020).

\section{Social Anxiety and Inhibition in the Relationship Between Minority Stress and Loneliness}

The original formulation of minority stress theory did not consider the specific pathways by which distal and proximal stress may confer risk for psychopathology. Extending the theory, Hatzenbuehler (2009) proposed several general psychological processes that link distal stress to psychopathology. Examples include pessimism, hopelessness, negative self-schemas, and emotional dysregulation. This psychological mediation framework aimed to show how minority stress "gets under the skin." Further extensions of this framework proposed the mediating roles of sexual orientation rejection sensitivity (Feinstein, 2020) and rumination (Timmins et al., 2020).

Few studies of minority stress and loneliness have examined the general psychological processes by which minority stress might lead to loneliness. An exception is Mereish and Poteat (2015), who found evidence for the role of shame. Our study addresses this shortcoming by examining the possible roles of social anxiety and social inhibition. Social anxiety is fear and worry of negative evaluation by others-either in specific situations or more globally-and can increase self-consciousness, inferiority, shame, and difficulty reading social cues (Knowles et al., 2015; Schneider et al., 2002). Notably, social anxiety is more prevalent among sexual minorities compared to others and is also associated with minority stress (Mahon et al., 2021). Social inhibition is the tendency to suppress expression of emotions or behaviors in order to avoid negative judgments (Asendorpf, 1993; Gest, 1997). A prospective study with the general population found that social anxiety predicts later loneliness (Lim et al., 2016). A partially prospective study, also with the general population, suggested that social inhibition predicts low sense of belonging (de Moor et al., 2018).

Cross-sectional studies have found that marginalization, concealment, internalized homonegativity, and sexual 
orientation rejection sensitivity are all associated with social anxiety (Cohen et al., 2016; Feinstein et al., 2012; Mereish \& Poteat, 2015; Pachankis et al., 2018). One study found that marginalization (specifically parental rejection), internalized homonegativity, and rejection sensitivity are all associated with social unassertiveness, a factor closely related to social inhibition (Pachankis et al., 2008). Another study found that marginalization is indirectly associated with social anxiety via internalized homonegativity and rejection sensitivity (Feinstein et al., 2012). Finally, a prospective daily diary study with young gay and bisexual men found that parental disapproval predicts public self-consciousness, and that selfconsciousness and concealment mediate the link between parental disapproval and general anxiety (Pachankis \& Bernstein, 2012). Given the findings above, it is plausible that minority stress could contribute to social anxiety and inhibition, which may in turn increase loneliness by motivating self-protective social withdrawal. Accordingly, we examine the roles of social anxiety and inhibition in the relationship between minority stress and loneliness.

\section{Protective Role of LGBTQ Community Involvement}

While several minority stress factors could increase loneliness, other factors could reduce minority stress, or at least its contribution to loneliness. One such factor is LGBTQ community involvement-having a supportive network of sexual minority friends or being a member of LGBTQ clubs, sports teams, or organizations (Meyer, 2003). Kuyper and Fokkema (2010) found that community involvement is negatively associated with loneliness among older Dutch LGB adults. The same relationship was found among Latino-American gay men living with HIV (Ramirez-Valles et al., 2005). Community involvement is also negatively associated with concealment motivation and internalized homonegativity (Bissonette \& Syzmanski, 2019; Foster-Gimbel et al., 2020; Frost \& Meyer, 2009; Kuyper \& Fokkema, 2010; Velez \& Moradi, 2016). Moreover, in studies of sexual minority adults in the USA and Hong Kong, associations between marginalization, internalized homonegativity, and poor psychological well-being were lower among people who were higher in various forms of LGBTQ community involvement (Chan \& Mak, 2021; Salfas et al., 2019; Toomey et al., 2011; Velez \& Moradi, 2016; see also Ramirez-Valles et al., 2005).

Although community involvement might increase marginalization by increasing one's exposure as a sexual minority (Bissonette \& Syzmanski, 2019; LeBeau \& Jellison, 2009), it offers several possible benefits that could concurrently reduce proximal stress and buffer its impact on loneliness. LGBTQ community involvement can provide a supportive social network which increases comfort with one's sexuality, validates one's experiences of marginalization, promotes adaptive reappraisals of marginalization, and fosters a sense of acceptance, belonging, and understanding (Cox et al., 2010; Kuyper \& Fokkema, 2010; LeBeau \& Jellison, 2009; Roberts \& Christens, 2021; Velez \& Moradi, 2016; Westefeld et al., 2001). Community involvement may also promote empowerment, personal control, self-efficacy, and self-esteem (Heath \& Mulligan, 2008; LeBeau \& Jellison, 2009; Ramirez-Valles et al., 2005; van Lisdonk \& Kuyper, 2015; Wernick et al., 2014; Westefeld et al., 2001). These factors are prospectively associated with decreased loneliness (Newall et al., 2014; Spithoven et al., 2017; Vanhalst et al., 2013). Given these lines of evidence, we examine whether LGBTQ community involvement is negatively associated with loneliness in a global sample. We also examine whether it is positively associated with marginalization, but negatively associated with proximal stress, and whether the links between marginalization, proximal stress, social anxiety/inhibition, and loneliness are weaker among those who are more community-involved.

\section{Dispositional Negative Affectivity as a Possible Confounding Factor}

Several researchers argue that studies of subjectively reported discrimination often overlook the confounding effect of personality traits (Bailey, 2020; Lilienfeld, 2017). Perceptions of marginalization and its subjective impact, along with rejection sensitivity and loneliness, may all be partly influenced by general negative affectivity (NA). This is an inherent and enduring disposition to experience dysphoria, anxiety, and irritability across situations (Denollet, 2005; Watson \& Clark, 1984). People high in NA have a negative view of themselves and others, and are more likely to perceive benign or ambiguous situations in a negative or threatening manner (Brief et al., 1988; Watson \& Clark, 1984). In addition, a longitudinal study with adults found that negative affectivity predicts rejection sensitivity in early childhood (Araiza et al., 2020). In addition, a longitudinal study with adults found that neuroticism — closely related to NA-predicts loneliness over 15 years (Mund \& Neyer, 2016). We examine whether dispositional negative affectivity may confound the relationship between minority stress and loneliness, especially since our measures of marginalization are affectively laden (e.g., measuring not only the frequency of microaggressions but also how much a person is bothered by them).

\section{The Current Study}

We proposed a structural equation model (SEM) which includes direct and indirect associations between distal minority stress (i.e., marginalization), proximal minority stress (i.e., internalized homonegativity, concealment, stigma preoccupation), social anxiety, social inhibition, 


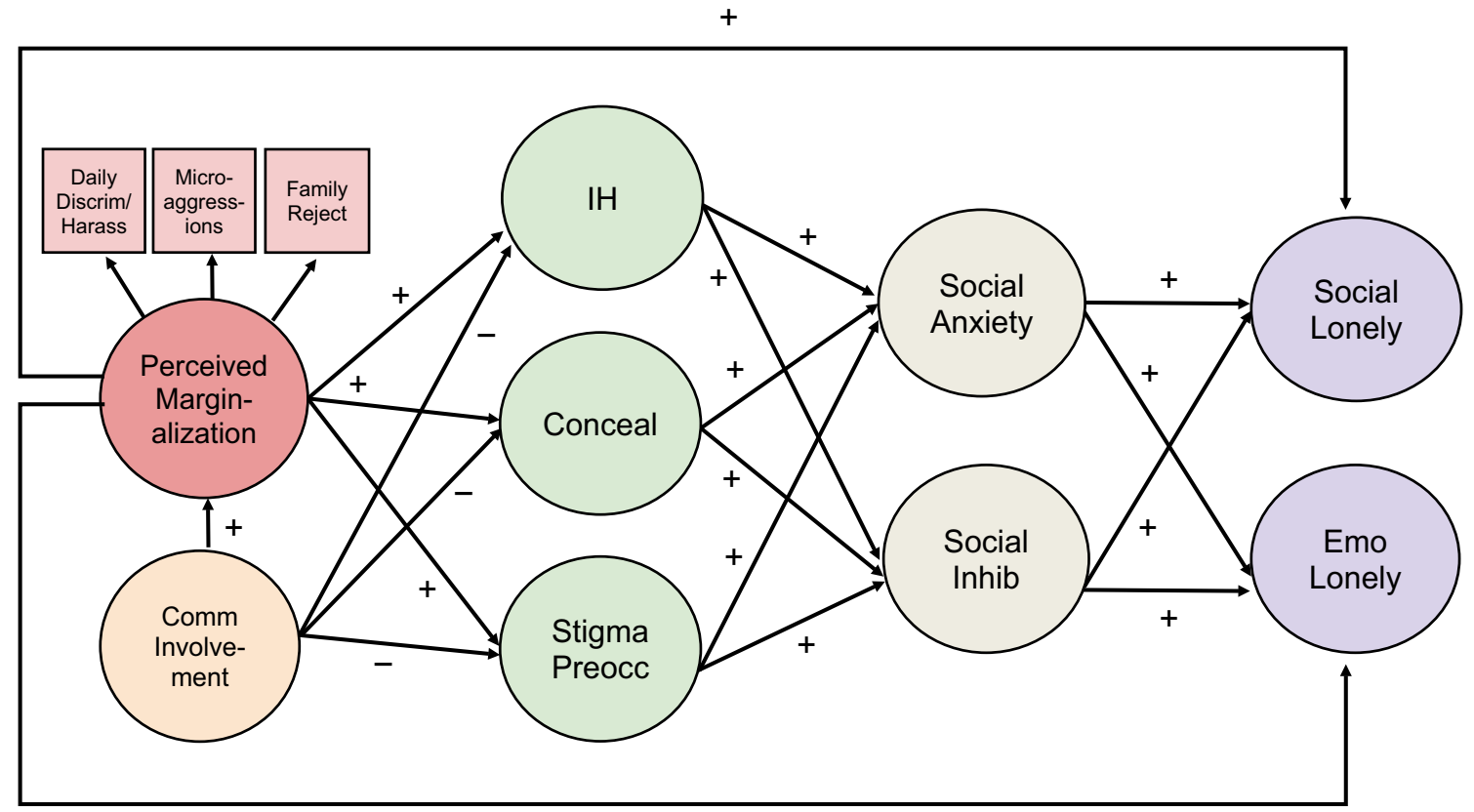

$+$

Fig. 1 Proposed structural equation model linking marginalization and loneliness. Notes: Daily Discrim/Harass = everyday discrimination and harassment, Family Reject $=$ family rejection, Comm Involvement $=$ community involvement, $\mathrm{IH}=$ internalized homonegativity, Conceal $=$ concealment, Stigma Preocc $=$ stigma preoccupation, Social Inhib $=$ social inhibition, Social Lonely $=$ social loneliness, Emo Lonely = emotional loneliness. For ease of presen-

community involvement, and loneliness (Fig. 1). Unlike previous studies, we examine both social and emotional loneliness, as they may have different associations with minority stress, social anxiety, inhibition, and community involvement. We propose several hypotheses based on our conceptual model:

H1: Marginalization (defined as perceived experiences of everyday discrimination/harassment, microaggressions, and family rejection) is positively associated with both social and emotional loneliness.

H2: Marginalization is positively associated with internalized homonegativity, concealment of sexual orientation, and stigma preoccupation.

H3: Internalized homonegativity, concealment, and stigma preoccupation are positively associated with social anxiety and inhibition, and with social and emotional loneliness (for simplicity, Fig. 1 only shows associations with social anxiety/ inhibition).

H4: Social anxiety and inhibition are positively associated with social and emotional loneliness. tation, direct associations between community involvement/proximal stress and both forms of loneliness are not shown, nor are direct associations between marginalization/community involvement and social anxiety/inhibition. We also do not show the a priori correlations between social anxiety and inhibition, and between both forms of loneliness

H5: Marginalization is positively associated with social and emotional loneliness via indirect relationships with internalized homonegativity, concealment, and stigma preoccupation.

H6: Marginalization is positively associated with social and emotional loneliness via indirect relationships with internalized homonegativity, concealment, and stigma preoccupation, and, in turn, via social anxiety and social inhibition (i.e., serial indirect associations).

H7: LGBTQ community involvement is positively associated with marginalization.

H8: LGBTQ community involvement is negatively associated with internalized homonegativity, concealment, stigma preoccupation, and both forms of loneliness (for simplicity, Fig. 1 does not show direct associations with loneliness).

H9: All associations in the model are weaker among those who are higher in LGBTQ community involvement (i.e., moderation).

H10: All associations decline after controlling for dispositional general negative affectivity. 


\section{Method}

\section{Participants}

Our sample was 7856 sexual minority adults from 85 countries (30\% from non-Western countries), with $20 \%$ living in suburban areas and $22 \%$ in small towns or rural areas. They were aged $18-88(M=32.91, S D=14.31, M d n=27)$, with $52 \%$ identifying as men, $38 \%$ as women, $4 \%$ as transgender men or women, and $6 \%$ as other (with non-binary as the most common fill-in response). Fifty-six percent identified as gay/ lesbian/homosexual, $15 \%$ as mostly gay/lesbian/homosexual, $17.5 \%$ as bisexual, $7 \%$ as pan/polysexual, and $4.5 \%$ as queer. Thirty percent identified as non-White and a little over half (53\%) were partnered. Table 1 provides detailed demographic characteristics.

\section{Data Collection}

After receiving ethics approval, we conducted an online survey during summer and fall 2016. To reach a global audience, we used social media click-ads, asking users aged $18+$ to participate in a study about "LGBTQ social relationships and well-being" (a minority of ads also used the term "mental health"). Some $78 \%$ of respondents in the current analysis found the survey via demographically targeted Facebook ads, 4\% via targeted Instagram ads, 5\% via notices on LGBTQ Facebook groups, and the rest via other websites (e.g., Tumblr, Reddit) or email. The paid ads were targeted to users who had explicitly indicated in their profile, either publicly or privately, that they were interested in people of the same gender or in LGBTQ topics. To reach people not as open about their sexual orientation, we targeted the same ads for a limited time to people who specified no sexual preference at all. We also ran a generic ad referencing "social relationships and well-being," with no mention of sexual orientation; $4.5 \%$ of respondents in the current analysis were reached this way. To maximize diversity, advertising was done purposively to ensure sufficient respondents of various ages, ethnicities, relationship statuses, political orientations, and regions. Ads were run prior to Facebook's 2018 guidelines that removed the ability to target ads by sexual orientation and race.

Social media advertising has been used successfully in previous studies of hard-to-reach populations, including sexual minorities (King et al., 2014; Thornton et al., 2016). Although not without its risks and limitations (Littler \& Joy, 2021), this method allows recruitment of LGBTQ sub-populations that are underrepresented in research, including older adults, those in non-Western and rural regions, and those not highly involved in the LGBTQ community. The latter is important because people higher in community involvement-who are often the primary source for minority stress
Table 1 Demographic characteristics

\begin{tabular}{|c|c|c|}
\hline Characteristic & $n$ & Percent or Average \\
\hline Age & 7856 & $\begin{array}{l}M=32.91 \\
S D=14.31 \\
M d n=27 \\
\text { Range }=18-88\end{array}$ \\
\hline \multicolumn{3}{|l|}{ Sex assigned at birth } \\
\hline Male & 4282 & $54.5 \%$ \\
\hline Female & 3572 & $45.5 \%$ \\
\hline \multicolumn{3}{|l|}{ Gender identity } \\
\hline Male & 4073 & $52 \%$ \\
\hline Female & 3017 & $38 \%$ \\
\hline Transgender: male-to-female* & 120 & $1.5 \%$ \\
\hline Transgender: female-to-male* & 206 & $2.5 \%$ \\
\hline Other, including non-binary & 440 & $6 \%$ \\
\hline \multicolumn{3}{|l|}{ Sexual orientation } \\
\hline Gay/lesbian/homosexual & 4417 & $56 \%$ \\
\hline Mostly gay/lesbian/homosexual & 1177 & $15 \%$ \\
\hline Bisexual & 1362 & $17.5 \%$ \\
\hline Pan/polysexual & 543 & $7 \%$ \\
\hline Queer & 357 & $4.5 \%$ \\
\hline \multicolumn{3}{|l|}{ Ethnoracial identity } \\
\hline White & 5481 & $70 \%$ \\
\hline Latinx/Hispanic & 949 & $12 \%$ \\
\hline Asian/Pacific Islander & 597 & $7.5 \%$ \\
\hline African/Black/Caribbean & 192 & $2.5 \%$ \\
\hline Arab/Middle Eastern & 60 & $1 \%$ \\
\hline Indigenous/Aboriginal & 62 & $1 \%$ \\
\hline Mixed/Multi & 455 & $6 \%$ \\
\hline Other & 60 & $1 \%$ \\
\hline \multicolumn{3}{|l|}{ Global region } \\
\hline North America & 2979 & $38 \%$ \\
\hline Latin America and Mexico & 1080 & $14 \%$ \\
\hline UK and Ireland & 871 & $11 \%$ \\
\hline Western Europe (Other) & 815 & $10.5 \%$ \\
\hline Eastern Europe & 673 & $8.5 \%$ \\
\hline Asia & 558 & $7 \%$ \\
\hline Australia and New Zealand & 466 & $6 \%$ \\
\hline South Africa & 348 & $4.5 \%$ \\
\hline Middle East and North Africa & 66 & $1 \%$ \\
\hline \multicolumn{3}{|l|}{ Geographic type } \\
\hline Urban & 4570 & $58 \%$ \\
\hline Suburban & 1569 & $20 \%$ \\
\hline Rural/Small Town & 1694 & $22 \%$ \\
\hline Partnered & 4136 & $53 \%$ \\
\hline $\begin{array}{l}\text { Comfort with Income } \\
\quad(1=\text { Not at all comfortable } \\
7=\text { Extremely comfortable })\end{array}$ & 7550 & $\begin{array}{l}M=4.19 \\
S D=1.82 \\
M d n=4\end{array}$ \\
\hline
\end{tabular}

*Includes individuals whose gender identity is discordant with their sex assigned at birth, but who do not identify as transgender. Ns may not equal 7,856 due to small proportions of missing responses. Percentages may not equal $100 \%$ due to rounding 
research-may differ in meaningful ways from those who are less community-involved (e.g., in real or perceived exposure to minority stress, or motivation for participating in research; Kuyper et al., 2016; Meyer \& Wilson, 2009).

Participants completed the survey anonymously using Qualtrics. Given its length, participants were able to pause and resume within two weeks. Ninety-four percent completed on the same day. To flag inattentive responding, we placed four "attention check" items at equal intervals throughout the survey (e.g., "Select answer 3 for this question"). Of those who completed most of the survey, the failure rate for the first three attention checks was $2-2.5 \%$. For the final attention check, failure was higher, at $13.5 \%$. We attribute this to its location at the end of the survey (i.e., fatigue) and its suboptimal placement in a question matrix where it was easy to miss.

To reduce comprehension problems, we advertised to individuals whose social media profiles indicated that they understood English. We also examined the internal consistency of responses across countries and races/ethnicities; results suggested that individuals comprehended questions in a similar manner.

As an incentive, participants could enter a draw for one of several Amazon gift cards ranging from $\$ 20-\$ 200$ USD or a donation to a charity of their choice.

\section{Screening and Eligibility}

A total of 23,458 respondents completed the screening section of the survey (informed consent and basic demographics). Of these, 15,830 were self-identified sexual minorities, of whom 14,449 chose to start the main part of the survey (i.e., detailed questions about sexuality). This does not include 986 people who identified as questioning, asexual, or other. We did not include these individuals in the current analysis because they were not shown all of the required minority stress scales. As most of these scales refer to sexual orientation (e.g., being LGBTQ, being attracted to people of the same gender), we felt that many of these respondents would find the scales to be inapplicable, confusing, or inappropriate. Moreover, for those who had selected "other" and typed a response, it was not possible to determine if they were sexual minorities and thus to present them with all of the minority stress scales. We also excluded those who identified as straight/heterosexual or mostly straight/heterosexual $(n=6642)$; they had completed many of the same scales as sexual minorities (e.g., loneliness, social anxiety), but not all of the ones required for the current analysis. Based on their Kinsey scores, some of these respondents could be classified as LGBTQ, but we did not include them because they did not specifically identify as sexual minorities.

\section{Survey Completion}

Of the initial 14,449 sexual minorities who started the main part of our survey, 10,377 (72\%) completed one-third of the survey (including the concealment, community involvement, and loneliness scales); 8563 (60\%) completed half the survey (including the social anxiety, inhibition, and negative affectivity scales); and 7974 (55\%) completed $\geq 80 \%$ of the survey (including the internalized homonegativity and stigma preoccupation scales, and at least the first marginalization scale-microaggressions). This completion rate is similar to that of other large online studies of loneliness (AARP, 2018), sexuality (BBC Internet Study; Reimers, 2007), and minority stress (Brewster et al., 2013; Community-Based Research Centre, 2017; Meyer et al., 2020). Those who quit prematurely (i.e., completed $<80 \%$ of the survey) appeared to do so because of survey length (median completion time $=73 \mathrm{~min}$ ), technical problems on smartphones, pausing and forgetting to resume the survey later, or trying to resume on a different device. Completers were slightly older ( $M$ age $=32.93, S D=14.31)$ compared to non-completers $(M$ age $=29.72, S D=12.14), t(14,410)=14.56, p<.001$. Queer and pan/polysexual respondents were more likely to complete compared to others $(62 \%$ versus $52 \%-56 \%), \chi^{2}(4)=36.49$, $p<.001$. There were also notable differences by ethnoracial identity: $61 \%$ of White respondents completed compared to $49 \%$ of Latinx/Hispanic individuals, 36\% of Asians, and 51\% of other races/ethnicities, $\chi^{2}(3)=407.28, p<.001$. Those who had started on a mobile device were also less likely to complete compared to those who had used a desktop computer (46\% versus $64 \%$ ), $\chi^{2}(1)=452.40, p<.001$ There were no meaningful differences in loneliness between completers and non-completers.

Of the 7974 respondents who completed at least $80 \%$ of the survey (our minimum acceptable completion rate), we excluded from the current analysis those who were under age $18(n=9)$, who specified no age $(n=15)$, who failed more than two attention checks $(n=62)$, who appeared to provide duplicate or nuisance responses $(n=18)$, or who were missing more than $20 \%$ of item-level data across all scales $(n=14)$. We did not exclude the small number of respondents with user-missing values on the marginalization, concealment, or community involvement scales, as many of these values appear to have been "not applicable" answers that respondents failed to record as such. Other respondents were missing values because they had quit the survey before completing the final two marginalization scales; we handled their missing data using imputation (see Missing Data section). The final sample was 7856 individuals. 


\section{Measures}

\section{Loneliness}

We used the 11-item de Jong Gierveld Loneliness Scale (de Jong Gierveld \& Kamphuis, 1985; de Jong Gierveld \& van Tilburg, 2021). Five positively worded items measure feelings of social embeddedness and sense of belonging (e.g., "There are plenty of people I can lean on when I have problems"). Six negatively worded items measure feelings of desolation and longing for an intimate attachment (e.g., "I miss having a really close friend"). Given the shame surrounding loneliness, as well as individuals' varying interpretations of the term, the words "lonely" and "loneliness" do not appear in the scale because they might lead to under-reporting, especially among men (Badal et al., 2021; Nicolaisen \& Thorsen, 2014; Victor et al., 2005).

Respondents indicated their agreement with each statement on a 5-point Likert-type scale $(1=$ Yes!, $2=$ Yes, $3=$ More or less, $4=N o, 5=N o !)$. Disagreeing with a positive item (No!, No, and More or less) indicated social loneliness and was assigned a score of 1 . Agreeing with a negative item (Yes!, Yes, and More or less) indicated emotional loneliness and was assigned a score of 1 . Scores were summed to yield separate totals for social and emotional loneliness. Although the scale was designed to be scored dichotomously (each item receiving 0 or 1 ), it can also be scored continuously. Our results were similar regardless of the method, but we report values based on the original method in order to facilitate comparison with previous studies.

The Loneliness Scale is valid and reliable for use in different countries and among different ethnicities (de Jong Gierveld \& Van Tilburg, 2010; Uysal-Bozkir et al., 2017; van Tilburg \& Fokkema, 2021; van Tilburg et al., 2004). In the current study, internal consistency reliability, as measured by McDonald's omega ( $\omega$ ), was good: 87 for emotional loneliness and .86 for social loneliness (omega, also called omega total, is interpreted similarly to alpha; McNeish, 2018).

\section{Marginalization}

We used three measures of marginalization. Microaggressions were measured with the Second-Class Citizen subscale of the Homonegative Microaggressions Scale (HMS; Wegner $\&$ Wright, 2016; Wright \& Wegner, 2012). This subscale refers to experiences that can make sexual minorities feel like lesser members of society. Respondents indicated how often in the last 12 months they have experienced each of eight events (e.g., "People telling you to act differently at work, school, or other professional settings in order to hide your sexual orientation"). Answers were recorded on a fivepoint Likert-type scale $(1=$ Never/Not applicable $; 5=$ Constantly). Unlike other scales, the HMS also asks respondents how much each experience bothered them $(1=$ Not at all not applicable; $5=$ A great deal). For each item, the two responses are multiplied; a total scale score is calculated as the mean of the products.

Although the HMS includes four subscales, we chose the Second-Class Citizen subscale to minimize survey length and because it contains items that are in the middle of the continuum of microaggressions. By contrast, the first subscale (Assumed Deviance) reflects intentional, hostile experiences (e.g., "How often have people assumed you were a pervert or deviant?"), while the other two (Assumptions of Gay Culture; Stereotypical Knowledge and Behavior) reflect more subtle experiences without intention to harm (e.g., "How often have people assumed you were knowledgeable in stereotypically gay tasks, like interior design for men or carpentry for women?"). The full HMS exhibits good factor structure, construct validity, and reliability, and the Second-Class Citizen Subscale is strongly correlated with internalized homonegativity, acceptance concerns, and other proximal stress factors (Wegner \& Wright, 2016; Wright \& Wegner, 2012). In the current study, reliability for this subscale was $\operatorname{good}(\omega=0.83)$.

We measured everyday discrimination/harassment and family rejection using the Daily Heterosexist Experiences Questionnaire (DHEQ; Balsam et al., 2013). Respondents indicate how often in the last 12 months they have experienced various heterosexist events, which are divided into nine subscales. For the current analysis, we used the 6-item Discrimination/Harassment subscale (e.g., "Being verbally harassed by strangers because you are LGBT"; "Being treated unfairly in stores or restaurants because of your sexual orientation"). We also used the 6-item Family of Origin subscale (e.g., "Your family avoiding talking about your LGBT identity"). We felt these subscales captured the more common forms of overt marginalization. We also administered the Victimization subscale, focusing on violent events, but did not use it in the current analysis due to very low item endorsement. The other subscales are only applicable to specific subgroups (e.g., parents, people with HIV) or reflect constructs that we measured using other scales (e.g., Isolation, Vigilance).

To focus on discrimination and harassment related to sexual orientation and not gender identity, we replaced "LGBT" with "sexual orientation" (e.g., "Being verbally harassed by strangers because of your sexual orientation"). For consistency, we also modified the response options to match those of the HMS, with subscale totals calculated in the same manner.

The DHEQ exhibits excellent content, construct, and criterion validity, and good reliability (Balsam et al., 2013; Morrison et al., 2016). In the current sample, reliability was good for Discrimination/Harassment $(\omega=0.83)$ and Family of Origin $(\omega=.79)$. 


\section{Internalized Homonegativity}

We used six modified items from the 11-item Personal Homonegativity subscale of Mayfield's (2001) Internalized Homonegativity Inventory (IHNI). This subscale assesses negative emotions and attitudes about one's sexual orientation (e.g., "I feel ashamed of my homosexuality"). To be more inclusive, we changed "my homosexuality" to "being attracted to people of the same gender" (here we did not use "sexual orientation" because, for purposes of another study, the scale was also administered to individuals with at least some same-gender desire but who consider themselves heterosexual; i.e., individuals who are unlikely to indicate feeling ashamed of being heterosexual). Responses were recorded on a six-point Likert-type scale $(1=$ Strongly disagree $; 6=$ Strongly agree $)$. A mean was calculated, with higher scores indicating greater internalized homonegativity.

Although the IHNI has two other subscales-Gay Affirmation and Morality of Homosexuality-we chose Personal Homonegativity to minimize survey length and because the items about negative emotions (e.g., shame, embarrassment, resentment) are most relevant to social anxiety, inhibition, and loneliness. In contrast, the Gay Affirmation subscale is about LGBTQ pride, and the Morality of Homosexuality subscale is about general attitudes rather than emotions.

The full scale demonstrates good validity and reliability (Choi et al., 2017). Although initially developed for gay men, the INHI is applicable to other groups and has been used in mixed-gender studies with modified wording (e.g., Kuyper $\&$ Bos, 2016). Due to space constraints, we chose the six items from the Personal Homonegativity subscale that best represented the construct and that exhibited the highest factor loadings in previous studies. Reliability of the reduced subscale was excellent $(\omega=.91)$.

\section{Sexual Orientation Concealment}

We used a modified version of the Concealment subscale of the Nebraska Outness Scale (NOS; Meidlinger \& Hope, 2014). Respondents specified how often they avoid indicating or implying their sexual orientation when interacting with five groups: immediate family, extended family, friends, coworkers/associates, and strangers $(0=$ Never $; 10=$ Always $)$. Examples of concealment include changing one's mannerisms or avoiding topics related to one's sexual orientation (e.g., discussion about same-gender partners). Unlike other scales, the NOS lacks a "not applicable" option (e.g., for people with no extended family). We added this option, which was selected by up to $5.5 \%$ of respondents, and assigned it a score of zero, given that the absence of a particular group of people in one's life reduces the frequency and burden of concealment. A mean is calculated, with higher scores indicating greater concealment. As with the IHNI, we replaced "sexual orientation" with "attraction to people of the same gender."

The NOS has a second subscale that also measures disclosure: how much one thinks other people are aware of one's sexual orientation. We chose the Concealment subscale because it is more strongly associated with mental distress (Meidlinger \& Hope, 2014; Schrimshaw et al., 2013). The full NOS exhibits good factor structure, construct validity, criterion validity, and reliability (Meidlinger \& Hope, 2014). In the current study, reliability for the Concealment subscale was $\operatorname{good}(\omega=.82)$.

\section{Stigma Preoccupation}

We used a modified version of the three-item Acceptance Concerns subscale of the Lesbian, Gay, and Bisexual Identity Scale (LGBIS; Mohr \& Kendra, 2011). The items assess a person's concerns about how they are perceived and judged because of their sexual orientation (e.g., "I often wonder whether others judge me for my sexual orientation"). Similar to the modified IHNI and NOS, we changed "my sexual orientation" to "my attraction to people of the same gender." Responses were recorded on a six-point Likert-type scale $(1=$ Strongly disagree $; 6=$ Strongly agree $)$. A mean was calculated, with higher scores indicating greater stigma preoccupation. As per Dyar et al. (2018), we refer to acceptance concerns as stigma preoccupation because the latter more accurately describes the items in this subscale. The full LGBIS is valid and reliable (Mohr \& Kendra, 2011) and has been tested for use in other countries (e.g., de Oliveira et al., 2012; Kemer et al., 2017). In the current study, reliability for Acceptance Concerns was good $(\omega=.85)$.

\section{LGBTQ Community Involvement}

We used five of seven items from the Involvement with Gay Community Scale (IGCS; Tiggemann et al., 2007). An example item is: "I am actively involved in the LGBTQ community." Responses were recorded on a seven-point Likert-type scale $(1=$ Not at all true of me; $7=$ Extremely true of $m e)$. A mean score was calculated, with higher scores indicating greater community involvement. The original scale has adequate validity and reliability (Tiggemann et al., 2007). Based on confirmatory factor analysis with the current sample, we deleted two reverse-keyed items with poor loadings that reduced model fit ("My closest friends are straight" and "When I go out, I generally spend time in venues not specifically aimed at LGBTQ individuals"). Reliability for the reduced five-item scale was good $(\omega=.82)$. 


\section{Social Anxiety}

We used the 12-item Brief Fear of Negative Evaluation Scale-Revised, a common measure of social anxiety (BFNE-II; Carleton et al., 2006). Unlike the LGBIS, this scale measures global fear of negative evaluation (e.g., "I am afraid that people will find fault with me"). Responses were recorded on a five-point Likert-type scale $(0=$ Not at all characteristic of me; $4=$ Extremely characteristic of me). The scale has excellent construct validity and reliability (Carleton et al., 2006, 2007). In the current study, reliability was excellent $(\omega=.93)$.

\section{Social Inhibition}

This was measured using the Social Inhibition subscale of the DS14 Type D Personality Scale (Denollet, 2005). Respondents indicated agreement with seven statements (e.g., "I find it hard to start a conversation"). Responses were recorded on a five-point Likert-type scale $(0=$ False; $4=$ True $)$. The DS14 has excellent construct validity and the Social Inhibition subscale correlates strongly with extraversion (Denollet, 2005). The scale is valid and reliable for use in many countries (e.g., Bergvik et al., 2010; Grande et al., 2010; Lim et al., 2011). In the current study, reliability was good $(\omega=.86)$.

\section{Negative Affectivity}

This trait was assessed using the Negative Affectivity subscale of the DS14. Respondents indicated agreement with seven items about the tendency to be dysphoric, irritable, or anxious (e.g., "I am often in a bad mood"; "I take a gloomy view of things"). Responses were recorded on a five-point Likert-type scale $(0=$ False $;=$ True $)$. The subscale is reliable and correlates strongly with neuroticism (Denollet, 2005). In the current study, reliability was good $(\omega=.87)$.

\section{Demographic Variables}

Respondents were asked "What sex were you assigned at birth, on your birth certificate?" Options were male and female. Gender identity was assessed by asking "How do you currently describe yourself?" Options were male, female, transgender male-to-female (MTF), transgender female-tomale (FTM), and other (please specify). We dummy-coded these as female and transgender/non-binary/other, with male as the reference. Within transgender/non-binary/other, we included 99 people whose gender identity was discordant with their sex assigned at birth, but who did not specifically identify as transgender; they did not differ significantly from self-identified transgender people on most scales. Sexual orientation was assessed by asking "What do you consider your sexual orientation to be, regardless of how you describe yourself to others?" Options were straight/heterosexual; mostly straight/heterosexual; gay/lesbian/homosexual; mostly gay/lesbian/homosexual; bisexual; queer; pansexual or polysexual; questioning/not yet sure; asexual; and other (please specify). Responses were dummy-coded as mostly gay/lesbian/homosexual; bisexual; queer; and pan/ polysexual, with gay/lesbian/homosexual as the reference.

Because race/ethnicity may affect minority stress processes (e.g., Shangani et al., 2020), we asked respondents "Which of the following best describes you?" Options were Aboriginal/Native/First Nations; African/African-American/Black; Arab/Middle Eastern; Asian; Caribbean; East Indian; Hawaiian Native/Pacific Islander; Latino/Latina/ Hispanic; White/Non-Hispanic White; Mixed/Multi; and Other. Responses were dummy-coded into Latinx/Hispanic, Asian, and Mixed/Multi/Other. White, the largest portion of the sample, was the reference. Following recommendations by Allen et al. (2011), we included Latino/Latina/Hispanic in the racial categories because some Latinx/Hispanic individuals, particularly in the USA, consider their ethnicity to be a race and express difficulty with separate race and ethnicity questions (Croll \& Gerteis, 2019). Those who selected Other and wrote that they were White, Caucasian, European, or an ethnicity commonly considered White or "Other White" in a given country (e.g., Irish/Celtic, Ukrainian, Mediterranean, Australian, New Zealand European/Pakeha) were recategorized into the White reference category (2\%). We did this to avoid mistakenly assigning respondents to the Mixed/ Multi/Other category (essentially a minority category) if it was unlikely, or unclear, that they were actually minorities.

Finally, respondents indicated their country of residence, which was dummy-coded into seven regions, with North America as the reference (UK, Western Europe, Eastern Europe, Latin America, South Africa, Australia/New Zealand, and Asia). They also indicated the type of region they lived in, which was dummy-coded into suburban and small/ rural/remote, with urban as the reference. Four percent did not provide these geographic details, mostly because they had quit the survey early; their details were inferred from IP addresses, with the caveat that some may have completed the survey in a country where they do not reside.

\section{Analytic Procedures}

\section{Missing Data}

For each scale, we computed mean scores if respondents answered at least $80 \%$ of items on the scale-our minimum acceptable completion rate. The same applied to computing parcel scores (see Model Specification below). Exceptions were the scales for social and emotional loneliness as well as stigma preoccupation, for which we required $100 \%$ completion, given that the first two scales are based on count data, 
not means, and the third contains only three items. These exceptions aside, if respondents were missing items, we computed mean scores or parcels using all available items (i.e., pro-rating). This method yields similar results to item-level multiple imputation, as long as missing data are low, sample size is large, reliability is high, and scales have at least five items (Parent, 2013).

Remarkably, $95 \%$ of respondents had no missing data and, for all but two scales, nearly $100 \%$ answered all items on each scale. Exceptions were scales for everyday discrimination/harassment and family rejection (both the frequency and distress components): for each of these scales, 3.2-3.9\% of respondents were missing at least one item, with $2.5-3 \%$ missing all items on the scale. About $75 \%$ of these respondents $(n=161)$ were missing all data on these scales because they had they quit the survey early. Data were not missing completely at random (Little's MCAR test: $\chi^{2}(111)=143.06$, $p=.022$ ). As missing data were partially predicted by observed variables, we handled them using stochastic regression imputation in AMOS, which is sufficient for low-level missingness (Schafer, 1999). Based on response patterns and comments, most of the remaining missing items appeared to be inapplicable to respondents, yet not marked as such (e.g., questions about one's partner or parents). We recoded these as "1" ("not at all/not applicable").

\section{Data Screening}

Scale distributions were roughly normal except for marginalization, internalized homonegativity, and concealment, which exhibited skewness $(+1.29$ to +2.91$)$ and/or kurtosis $(-0.85$ to +11.76$)$. This is unsurprising as most participants had low scores on these measures, consistent with other studies (e.g., Everett et al., 2019; Mereish \& Poteat, 2015; van Lisdonk \& Kuyper, 2015; Velez \& Moradi, 2016). In fact, roughly onethird of respondents scored 1 (the lowest possible score) for everyday discrimination/harassment, family rejection, and internalized homonegativity; $20 \%$ scored $0-1$ for concealment. Univariate and multivariate deviations from normality were confirmed by Q-Q plots and Mardia's coefficient (33.78, $p<.001)$.

As structural equation modeling can yield inaccurate estimates and standard errors in the presence of non-normal distributions, we log-transformed the total scores for all three marginalization scales and internalized homonegativity. This redistributed the tails somewhat, but despite lower skewness and kurtosis, the scales remained markedly L-shaped. The distribution for concealment worsened after transformation, so we used it in its original form. We retained all other transformed values and used bootstrapping to further compensate for deviations from normality. As a supplementary step, we conducted all analyses with and without log-transformations; the overall patterns of association and model fit statistics were similar between approaches, but associations were stronger using transformed values, so we report all results based on the latter.

\section{Model Specification}

To take full advantage of SEM's ability to account for measurement error and thus produce more accurate parameter estimates, we created latent variables (factors), each having multiple indicators. The marginalization factor was formed using mean scores for everyday discrimination/harassment, microaggressions, and family rejection. The stigma preoccupation factor was formed using the three items from the Acceptance Concerns subscale of the LGBIS. Remaining factors were formed via parceling, which involves grouping scale items into smaller subsets. Compared to individual items, parcels can improve reliability, reduce distributional violations, and decrease the number of parameters requiring estimation (Coffman \& MacCallum, 2005; Little et al., 2002).

We grouped items using the item-to-construct approach, also known as the factorial algorithm (Little et al., 2002). For most parcels, we further redistributed items to combine those with opposite skew, thus improving parcel distributions (Thompson \& Melancon, 1996). However, even after this approach, parcels for internalized homonegativity were still skewed, so we log-transformed them. For all scales, we achieved similar average factor loadings within parcels. Correlations between parcels and total scale scores were all high $(\geq .85)$, as were correlations between parcels, ranging from .60 to .85 , with most over .70 . While most scales were divided into three parcels, the community involvement, concealment, and social loneliness scales were divided into two, given their smaller number of items. Although three indicators/parcels per factor are ideal, two are acceptable if item communalities are high and the factors can be adequately identified (Kenny, 2012).

We linked the factors as per Fig. 1. For ease of presentation, the figure does not show the direct associations we added between community involvement/proximal stress and both forms of loneliness. While not specifically mentioned in our hypotheses, we also added direct associations between marginalization/community involvement and social anxiety/inhibition (also not shown in Fig. 1). Although adding these associations reduces model parsimony, excluding them essentially fixes them to zero, possibly inflating our theorized indirect associations (Hayes \& Preacher, 2013). We also included a priori correlations between social anxiety and inhibition, and between social and emotional loneliness (not shown). We did this to depict the conceptual and empirical similarity between these variables; however, as SEM does not permit latent endogenous variables to covary, we specified these associations by correlating their residual error terms (Kenny, 2011). 


\section{Main Analyses}

To test our model, we conducted structural equation modeling with AMOS 25 (Arbuckle, 2017). Our sample $(N=7856)$ had sufficient statistical power $(\geq .80)$ to detect even small effects (Cohen, 1988; Westland, 2010). It was also sufficient assuming the minimum recommendation of about ten respondents per estimated parameter (Jackson, 2003).

First, we tested the validity of our measurement model to ensure that all indicator variables loaded adequately onto their respective factors. Next, we added structural paths between factors and tested all hypothesized direct and indirect associations.

To handle non-normal data, we used bias-corrected bootstrapping with $95 \%$ confidence intervals, using 5000 samples from the original dataset. We also compared results before and after exclusion of multivariate outliers (Aguinis et al., 2013; Warren et al., 2011). For all analyses, we used maximum likelihood estimation.

We used several indices to assess the fit of the measurement and structural models: the comparative fit index (CFI), Tucker-Lewis Index (TLI), root-mean-square error of approximation (RMSEA), and standardized root-meansquare residual (SRMR). Good model fit is suggested by CFI and TLI values $\geq .95$ (Hu \& Bentler, 1999), although some researchers suggest higher values, with $\geq .97$ suggestive of good fit and $\geq .95$ suggestive of adequate fit (SchermellehEngel et al., 2003). For RMSEA and SRMR, values $\leq .05$ are suggestive of good fit (Browne \& Cudeck, 1993; Hu \& Bentler, 1999; Schermelleh-Engel et al., 2003).

As a measurement model may contribute strongly to overall fit even if the structural model exhibits poor fit (McDonald $\&$ Ho, 2002), we evaluated the fit of the measurement, structural, and composite models separately (O'Boyle \& Williams, 2011). We also inspected standardized residual covariances for localized misfit, which can be masked by global fit indices (Tomarken \& Waller, 2003). As these residual covariances tend to be inflated in large samples (Brown, 2015), we flagged values greater than 2.58 (i.e., significant at $p<.01$; Byrne, 2010). To verify if large residual covariances were due to sample size, we re-ran analyses with smaller samples comprising $25 \%$ and $50 \%$ of participants randomly drawn from the full sample.

If global fit was unsatisfactory, or standardized residual covariances indicated localized misfit, we examined modification indices for any theoretically defensible paths or error correlations that could be added (e.g., correlations between error terms of indicator variables or factors). Any such additions were added and tested iteratively. We did not delete small or statistically non-significant paths to improve fit as such paths are theoretically relevant and may be significant in replication samples or moderated mediation with different subgroups (Kline, 2016).
We checked that all associations were statistically significant and in the hypothesized directions. We also examined the size of parameters, but were cognizant that indirect associations are often small due to their multiplicative nature; these associations are even smaller when multiple serial mediators are used (Walters, 2019). Although we were primarily interested in whether indirect associations were consistent with theory, we also calculated effect sizes and expressed them in terms of relative magnitude. We did this by dividing each indirect association by the total association between marginalization and social/emotional loneliness (Preacher \& Kelley, 2011; Wen \& Fan, 2015).

To determine if associations in the model differed by community involvement (i.e., moderation), we added continuous latent variable interactions (e.g., marginalization x community involvement). We used double-mean-centering, which is recommended when variables are not normally distributed (Lin et al., 2010). For each latent moderation factor, we added correlated errors between product terms that shared common items. We probed statistically significant interactions using simple slopes tests, and reported associations between factors at three levels of community involvement: high (one standard deviation above the mean), medium (at the mean), and low (one standard deviation below the mean). As interaction effects in social science tend to be small, power to detect such effects can be low, even with large samples; thus, we probed interactions that were significant at the .10 level (Fairchild \& MacKinnon, 2009).

Finally, to determine if trait-level general negative affectivity was a potential confound in the relationships between minority stress, social anxiety, inhibition, and loneliness, we re-ran our SEM model after adding negative affectivity as a control. It was introduced as a latent factor with three indicator parcels, each loading $>.70$. To see if our use of affectively laden marginalization scales may have exacerbated any confounding influence of negative affectivity, we re-ran analyses using only the frequency component of each scale and excluding the evaluation of subjective impact (Lilienfeld, 2017).

Models were controlled for age, gender identity, sexual orientation, ethnoracial identity, and region. While results may differ as a function of these variables, these differences will be explored in detail in a separate study, using the same data. We did not control for partner status or income as these factors may mediate the link between marginalization and loneliness; controlling for them would reduce total associations. However, to reduce model complexity, we did not explicitly model these variables as mediators. We also did not control for method of recruitment (e.g., Facebook, Instagram, other website, or email) or device type (mobile versus desktop) as they were not associated with any scale scores. 
Table 2 Descriptive statistics and Pearson's correlations between major study variables

\begin{tabular}{|c|c|c|c|c|c|c|c|c|c|c|c|c|}
\hline & 1 & 2 & 3 & 4 & 5 & 6 & 7 & 8 & 9 & 10 & 11 & 12 \\
\hline 1. Discrim/harass & - & & & & & & & & & & & \\
\hline 2. Microaggress & .57 & - & & & & & & & & & & \\
\hline 3. Family reject & .46 & .48 & - & & & & & & & & & \\
\hline 4. Comm involve & .11 & .11 & .04 & - & & & & & & & & \\
\hline 5. IH & .21 & .21 & .21 & -.24 & - & & & & & & & \\
\hline 6. Concealment & .10 & .19 & .20 & -.24 & .44 & - & & & & & & \\
\hline 7. Stigma & .34 & .37 & .32 & -.17 & .55 & .44 & - & & & & & \\
\hline 8. Social anxiety & .24 & .25 & .18 & -.06 & .33 & .25 & .43 & - & & & & \\
\hline 9. Social inhib & .10 & .13 & .09 & -.17 & .22 & .22 & .25 & .41 & - & & & \\
\hline 10. Emo lonely & .18 & .20 & .17 & -.13 & .29 & .21 & .28 & .37 & .36 & - & & \\
\hline 11. Social lonely & .10 & .10 & .11 & -.14 & .21 & .18 & .19 & .23 & .36 & .61 & - & \\
\hline 12. Neg affect & .23 & .26 & .17 & -.10 & .29 & .19 & .32 & .53 & .47 & .49 & .36 & - \\
\hline Possible Range & $1-25$ & $1-25$ & $1-25$ & $1-7$ & $1-6$ & $0-10$ & $1-6$ & $0-48$ & $0-28$ & $0-6$ & $0-5$ & $0-28$ \\
\hline$M$ & 2.75 & 5.41 & 3.56 & 3.38 & 1.82 & 3.72 & 3.12 & 25.07 & 13.26 & 3.20 & 2.48 & 13.21 \\
\hline$S D$ & 2.70 & 3.84 & 3.82 & 1.46 & .99 & 2.69 & 1.37 & 11.40 & 6.50 & 2.17 & 1.79 & 6.14 \\
\hline Median & 1.67 & 4.50 & 1.83 & 3.20 & 1.50 & 3.60 & 3.00 & 25.00 & 13.00 & 3.00 & 2.00 & 13.00 \\
\hline Skew & .84 & -.19 & .68 & .51 & .64 & .34 & .15 & .09 & .05 & -.14 & .01 & .02 \\
\hline$S E$ of Skew & .03 & .03 & .03 & .03 & .03 & .03 & .03 & .03 & .03 & .03 & .03 & .03 \\
\hline Kurtosis & -.15 & -.77 & -.73 & -.51 & -.78 & -.85 & -.92 & -.84 & -.75 & -1.40 & -1.38 & -.59 \\
\hline$S E$ of Kurtosis & .06 & .06 & .06 & .06 & .06 & .06 & .06 & .06 & .06 & .06 & .06 & .06 \\
\hline Omega $(\omega)$ & .83 & .83 & .79 & .82 & .91 & .82 & .85 & .93 & .86 & .87 & .86 & .87 \\
\hline
\end{tabular}

Discrim/harass $=$ everyday discrimination/harassment, Microaggress $=$ microaggressions, Family reject $=$ family rejection, Comm involve $=$ community involvement, $\mathrm{IH}=$ internalized homonegativity, Stigma = stigma preoccupation, Social inhib = social inhibition, Social lonely $=$ social loneliness, Emo lonely=emotional loneliness, Neg affect=negative affectivity. Correlations, skewness, and kurtosis for everyday discrimination/harassment microaggressions, family rejection, and internalized homonegativity are based on log-transformed values. For all correlations, $p<.001$

\section{Results}

\section{Preliminary Analysis}

As seen in Table 2, participants exhibited relatively low levels of marginalization, concealment, and internalized homonegativity, and moderate levels of stigma preoccupation, social anxiety, inhibition, negative affectivity, and community involvement. Using cut-off values based on combined social and emotional loneliness scores (de Jong Gierveld \& van Tilburg, 2021), 47\% of respondents were moderately lonely, $18 \%$ very lonely, and $10 \%$ severely lonely. All zero-order correlations were significant and in the expected directions.

\section{Measurement Model}

All indicators loaded strongly onto their respective factors ( $>$.70, with most over .80). Only one indicator of marginalization (family rejection) had a somewhat lower factor loading (0.63), although this is unsurprising because the other two indicators (everyday discrimination/harassment and microaggressions) pertain to marginalization across all settings, not specifically to family.
Overall, the measurement model had a strong fit to the data: $\chi^{2}(216)=1846.53, p<.001 ; \mathrm{CFI}=.99 ; \mathrm{TLI}=.98 ; \mathrm{SRMR}=$ $.022 ;$ RMSEA $=.031,90 \%$ CI $[.030, .032]$. Nonetheless, $19 \%$ of the standardized residual covariances were $>2.58$. Although fairly well distributed, several of these residuals were concentrated around the second and third emotional loneliness parcels. Modification indices suggested adding a correlation between the error terms of these two parcels. As items with similar wording were found in both parcels ("I miss having people around me" and "I miss the pleasure of the company of others"), we felt that adding the correlation was justified. After this modification, model fit improved: $\chi^{2}(215)=1516$ $.12, p<.001 ; \mathrm{CFI}=.99$; TLI $=.99 ; \mathrm{SRMR}=.020$; RMSEA $=.028,90 \% \mathrm{CI}[.026, .029]$. Ten percent of residual covariances remained over 2.58; however, when using our smaller samples, almost all were within normal range and the larger ones were broadly scattered, but some still clustered around the third emotional loneliness parcel. Modification indices did not suggest further substantive changes, so we were satisfied with our minimally adjusted measurement model. 


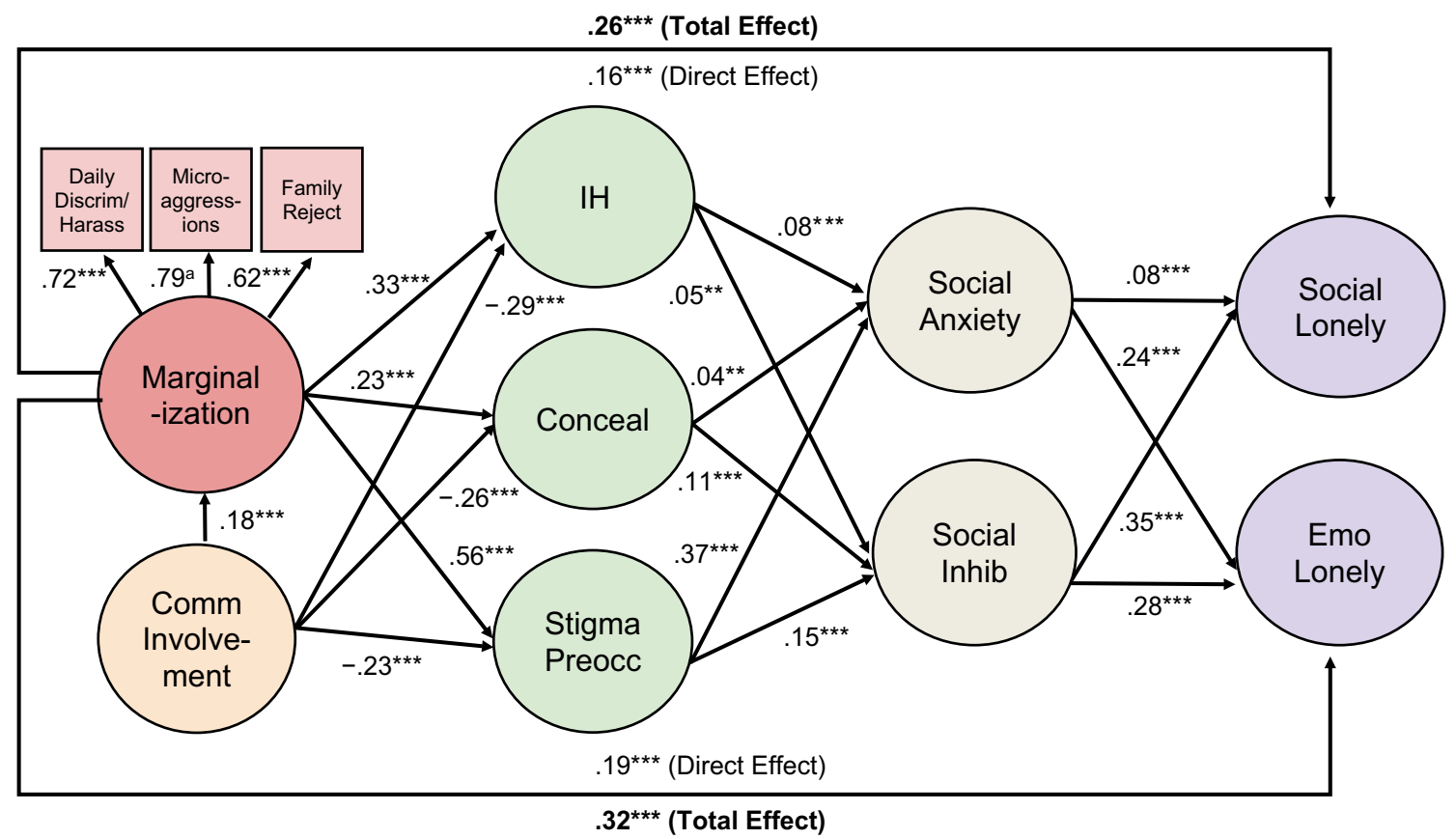

Fig. 2 Structural equation model linking marginalization and loneliness. Notes: Daily Discrim/Harass = everyday discrimination/harassment, Family Reject $=$ family rejection, Comm Involvement $=$ community involvement, $\mathrm{IH}=$ internalized homonegativity, Conceal = concealment, Stigma Preocc $=$ stigma preoccupation, Social Inhib $=$ social inhibition, Social Lonely $=$ social loneliness, Emo Lonely $=$ emotional loneliness. For ease of presentation, direct associations between community involvement/proximal stress and both forms of loneliness are not shown, nor are direct associations between marginalization/community involvement

\section{Structural Model}

The initial model was an acceptable fit to the data: $\chi^{2}(503)=5093.05, p<.001 ; \mathrm{CFI}=.97 ; \mathrm{TLI}=.94$; $\mathrm{SRMR}=.024 ; \mathrm{RMSEA}=.034,90 \% \mathrm{CI}[.033, .035]$. However, inspection of standardized residual covariances and modification indices suggested correlating the error terms of all three proximal stress factors. Because of the conceptual and empirical similarity between the factors, we felt it was appropriate to do so. Following these adjustments, residual covariances $>2.58$ declined to $7 \%$ and were less than $3 \%$ in our smaller samples. As modification indices suggested no other substantive areas to improve fit, we made no further adjustments.

The revised model fit the data well: $\chi^{2}(500)=3092.15, p<.001$; $\mathrm{CFI}=.98 ; \mathrm{TLI}=.97 ; \mathrm{SRMR}=.015 ; \mathrm{RMSEA}=.026,90 \% \mathrm{CI}$ $[.025, .027]$. We decomposed the RMSEA values for the measurement and structural models. RMSEA for the structural model was $.024,90 \%$ CI $[.023, .025]$. Thus, we have confidence that the fit indices for the entire model reflected goodness of fit for both the measurement and structural models. In addition, model fit and patterns of association were similar with and without the inclusion of the top $5 \%$ and $10 \%$ of multivariate outliers. and social anxiety/inhibition (see Table 3 for coefficients). The following correlated residuals (essentially factor correlations) are also not shown: internalized homonegativity and concealment $(r=.37, p<.001)$, internalized homonegativity and stigma preoccupation $(r=.51, p<.001)$, concealment and stigma preoccupation $(r=.39, p<.001)$, social anxiety and social inhibition $(r=.35, p<.001)$, and social and emotional loneliness $(r=.74, p<.001)$. All values are standardized regression coefficients. ${ }^{\text {a }}$ Strongest path fixed to 1.0 for statistical identification, thus $p$-value cannot be computed. $* * * p<.001, * * p<.01$

\section{Structural Relationships}

Hypotheses 1-4 were generally supported, as seen in Fig. 2 and Table 3. Total associations between marginalization and loneliness were positive (Hypothesis 1). Based on empirically derived guidelines for interpreting effect sizes in social psychology (Lovakov \& Agadullina, 2021), these associations were moderate: for social loneliness, $\beta=.26, p<.001$, $95 \%$ CI $[.22, .29]$; for emotional loneliness, $\beta=.32, p<.001$, $95 \%$ CI $[.28, .35]$. Marginalization was also positively associated with all three proximal stressors: internalized homonegativity, concealment, and, especially, stigma preoccupation (Hypothesis 2). Associations were moderate to large. In turn, stigma preoccupation showed a positive, moderate association with social anxiety, and a smaller positive association with inhibition (Hypothesis 3). The other two proximal stressors-internalized homonegativity and concealmentwere also positively associated with social anxiety and inhibition, but to a lesser extent. In mixed support of Hypothesis 3 , internalized homonegativity had a small, positive association with both social and emotional loneliness, while concealment had a small, positive association with social loneliness, but a negligible positive association with emotional loneliness. 
In opposition to Hypothesis 3, there were small, non-significant negative associations between stigma preoccupation and both social and emotional loneliness. (For simplicity, direct associations between proximal stress and loneliness are only reported in Table 3, not Fig. 2). Finally, supporting Hypothesis 4, social anxiety and inhibition were positively associated with both social and emotional loneliness. These relationships were moderate, with the exception of the relationship between social anxiety and social loneliness, which was small.

As shown in Tables 4 and 5, indirect associations between marginalization and loneliness were mostly in the expected directions, supporting Hypotheses 5 and 6. Although individual associations were small in absolute terms, in combination they amounted to $37 \%$ of the total association between marginalization and social loneliness, and $41 \%$ of the total association between marginalization and emotional loneliness. Stigma preoccupation played a key role in the indirect associations: marginalization was positively associated with both forms of loneliness via stigma preoccupation and social anxiety, and via stigma preoccupation and social inhibition. In addition to these positive serial associations involving social anxiety/inhibition, there were small, non-significant negative associations between marginalization and both forms of loneliness via stigma preoccupation alone. Marginalization was also positively associated with both forms of loneliness via internalized homonegativity alone, and positively associated with social loneliness via concealment alone. Other indirect associations were consistent with hypotheses, but much smaller.

Considering both direct and indirect associations plus covariates, our model accounted for $25 \%$ of variance in social loneliness and $35 \%$ of variance in emotional loneliness. The model also accounted for $23 \%$ of variance in internalized homonegativity, $21 \%$ in concealment, $38 \%$ in stigma preoccupation, $30 \%$ in social anxiety, and $15 \%$ in social inhibition.

\section{Role of Community Involvement}

As shown in Fig. 2 and Table 3, there was a small positive association between community involvement and marginalization, as expected (Hypothesis 7). There were also moderate negative associations between community involvement and all three proximal stress factors, and smaller negative associations with both forms of loneliness (Hypothesis 8). Total associations (direct and indirect) between community involvement and loneliness were small: for social loneliness, $\beta=-.18$, $p<.001,95 \%$ CI $[-.21,-.15]$; for emotional loneliness, $\beta=-.13, p<.001,95 \%$ CI $[-.16,-.10]$. About $45 \%$ of the total association between community involvement and social loneliness was indirect, as was $40 \%$ of the total association between community involvement and emotional loneliness.

After including interaction terms between community involvement and other latent factors, model fit remained strong, albeit slightly weaker than the original model because our chosen fit statistics penalize for model complexity: $\chi^{2}(2282)=17,412.26, p<.001 ; \mathrm{CFI}=.96$; TLI $=.95$; $\mathrm{RSMR}=.026 ; \mathrm{RMSEA}=.029,90 \%$ CI $[.029, .030]$. Several interactions were statistically significant and in the expected directions, but they were fairly small, providing muted support for Hypothesis 9. For people higher in community involvement, interaction terms indicated somewhat weaker associations between marginalization and internalized homonegativity (interaction $\beta=-.06, p<.001$ ), concealment (interaction $\beta=-.03, p=.039$ ), and stigma preoccupation (interaction $\beta=-.03, p=.007$ ). There were also weaker associations between stigma preoccupation and social anxiety (interaction $\beta=-.07, p=.045$ ), and between social inhibition and social loneliness (interaction $\beta=-.04, p=.020$ ). However, in contrast to Hypothesis 9, greater community involvement was associated with somewhat stronger relationships between concealment and social anxiety (interaction $\beta=.03, p=.062$ ). Community involvement did not significantly moderate the direct associations between marginalization and emotional loneliness $(\beta=.01, p=.822)$, or between marginalization and social loneliness $(\beta=.01, p=.755)$. Table 6 lists simple slopes for high, average, and low community involvement.

\section{Role of Dispositional Negative Affectivity}

After adjusting for general negative affectivity (a latent factor with three indicators, all loading over .80 ), the model was still a good fit to the data: $\chi^{2}(601)=4271.84 ; \mathrm{CFI}=.98$; $\mathrm{TLI}=.96$; $\mathrm{SRMR}=.016$; $\mathrm{RMSEA}=.028,90 \%$ CI [.027, .029]. However, supporting Hypothesis 10, total associations between marginalization and loneliness declined by about half (54\% reduction for social loneliness and 53\% reduction for emotional loneliness) (Fig. 3). Direct associations with social and emotional loneliness declined by $31 \%$ and $37 \%$, while indirect associations declined by 90 and $77 \%$. When using frequency-only measures of marginalization, the inclusion of negative affectivity reduced the total associations between marginalization and both forms of loneliness to a slightly lesser extent (47\% reduction for social loneliness and 50\% reduction for emotional loneliness). The adjusted model accounted for $30 \%$ of variance in social loneliness, $43 \%$ in emotional loneliness, $26 \%$ in internalized homonegativity, $22 \%$ in concealment, $40 \%$ in stigma preoccupation, $46 \%$ in social anxiety, and $33 \%$ in social inhibition. 
Table 3 Direct associations (standardized)

\begin{tabular}{|c|c|c|c|c|c|}
\hline \multirow[t]{2}{*}{ Predictor } & \multirow[t]{2}{*}{ Outcome } & \multirow[t]{2}{*}{$\beta$} & \multicolumn{2}{|l|}{$95 \% \mathrm{CI}$} & \multirow[t]{2}{*}{$p$} \\
\hline & & & Lower & Upper & \\
\hline \multirow[t]{7}{*}{ Marginalization } & Social loneliness & .16 & .12 & .20 & $<.001$ \\
\hline & Emotional loneliness & .19 & .15 & .23 & $<.001$ \\
\hline & Internalized homonegativity & .33 & .30 & .36 & $<.001$ \\
\hline & Concealment & .23 & .20 & .26 & $<.001$ \\
\hline & Stigma preoccupation & .56 & .53 & .58 & $<.001$ \\
\hline & Social anxiety & .04 & .01 & .08 & .019 \\
\hline & Social inhibition & .01 & -.04 & .04 & .932 \\
\hline \multirow[t]{4}{*}{ Internalized homonegativity } & Social anxiety & .08 & .05 & .11 & $<.001$ \\
\hline & Social inhibition & .05 & .02 & .09 & .002 \\
\hline & Social loneliness & .09 & .05 & .12 & $<.001$ \\
\hline & Emotional loneliness & .13 & .10 & .17 & $<.001$ \\
\hline \multirow[t]{4}{*}{ Concealment } & Social anxiety & .04 & .01 & .07 & .006 \\
\hline & Social inhibition & .11 & .07 & .14 & $<.001$ \\
\hline & Social loneliness & .07 & .03 & .10 & $<.001$ \\
\hline & Emotional loneliness & .01 & -.02 & .04 & .671 \\
\hline \multirow[t]{4}{*}{ Stigma preoccupation } & Social anxiety & .37 & .33 & .41 & $<.001$ \\
\hline & Social inhibition & .15 & .11 & .19 & $<.001$ \\
\hline & Social loneliness & -.03 & -.08 & .01 & .124 \\
\hline & Emotional loneliness & -.04 & -.08 & .01 & .098 \\
\hline \multirow[t]{2}{*}{ Social anxiety } & Social loneliness & .08 & .05 & .11 & $<.001$ \\
\hline & Emotional loneliness & .24 & .21 & .27 & $<.001$ \\
\hline \multirow[t]{2}{*}{ Social inhibition } & Social loneliness & .35 & .32 & .38 & $<.001$ \\
\hline & Emotional loneliness & .28 & .25 & .30 & $<.001$ \\
\hline \multirow[t]{8}{*}{ Community involvement } & Marginalization & .18 & .16 & .21 & $<.001$ \\
\hline & Internalized homonegativity & -.29 & -.31 & -.26 & $<.001$ \\
\hline & Concealment & -.26 & -.28 & -.23 & $<.001$ \\
\hline & Stigma preoccupation & -.23 & -.26 & -.21 & $<.001$ \\
\hline & Social anxiety & .01 & -.01 & .04 & .324 \\
\hline & Social inhibition & -.14 & -.17 & -.11 & $<.001$ \\
\hline & Social loneliness & -.10 & -.14 & -.07 & $<.001$ \\
\hline & Emotional loneliness & -.08 & -.11 & -.05 & $<.001$ \\
\hline
\end{tabular}

\section{Discussion}

\section{Relationships Between Minority Stress, Social Anxiety/Inhibition, and Loneliness}

Our findings provide additional support for minority stress theory by demonstrating direct and indirect associations between marginalization, proximal stress, and loneliness. Our findings also extend Hatzenbuehler's (2009) psychological mediation framework by examining the roles of social anxiety and inhibition in the relationship between minority stress and loneliness.

Notably, we found that marginalization was more strongly associated with stigma preoccupation than with concealment and internalized homonegativity. While marginalization likely increases fear of judgment and rejection, it might not necessarily increase self-hatred. Indeed, for some sexual minorities, it may even generate feelings of pride, countering negative impacts. In contrast, some people may internalize negative attitudes without having been marginalized themselves (e.g., by observing others being marginalized). Similarly with concealment, some who have been marginalized might react by hiding their sexual orientation, whereas others might feel even more motivated to be "out and proud." These contrasting reactions may explain why the correlations between marginalization, internalized homonegativity, and concealment were relatively smaller.

Turning to associations between proximal stress and social anxiety/inhibition, we found that stigma preoccupation was most strongly associated with these two variables. It also played played the most prominent role in the indirect associations between marginalization and loneliness. The 
Table 4 Indirect associations between marginalization and social loneliness

\begin{tabular}{|c|c|c|c|c|c|c|}
\hline \multirow[t]{2}{*}{ Indirect Association } & \multirow[t]{2}{*}{$\beta$} & \multirow[t]{2}{*}{$B$} & \multicolumn{2}{|l|}{$95 \% \mathrm{CI}$} & \multirow[t]{2}{*}{$p$} & \multirow{2}{*}{$\begin{array}{l}\text { Relative } \\
\text { magnitude }\end{array}$} \\
\hline & & & Lower & Upper & & \\
\hline \multicolumn{7}{|l|}{ Serial indirect associations } \\
\hline Marginalization $\rightarrow$ Stigma Preocc $\rightarrow$ Inhibition $\rightarrow$ Soc Loneliness & .029 & .080 & .057 & .106 & $<.001$ & $11 \%$ \\
\hline Marginalization $\rightarrow$ Stigma Preocc $\rightarrow$ Soc Anxiety $\rightarrow$ Soc Loneliness & .017 & .047 & .028 & .066 & $<.001$ & $7 \%$ \\
\hline Marginalization $\rightarrow$ Concealment $\rightarrow$ Inhibition $\rightarrow$ Soc Loneliness & .008 & .023 & .016 & .032 & $<.001$ & $3 \%$ \\
\hline Marginalization $\rightarrow$ Concealment $\rightarrow$ Soc Anxiety $\rightarrow$ Soc Loneliness & .001 & .002 & .001 & .004 & .004 & $<1 \%$ \\
\hline Marginalization $\rightarrow$ IH $\rightarrow$ Inhibition $\rightarrow$ Soc Loneliness & .006 & .017 & .007 & .029 & .002 & $2 \%$ \\
\hline Marginalization $\rightarrow \mathrm{IH} \rightarrow$ Soc Anxiety $\rightarrow$ Soc Loneliness & .002 & .006 & .003 & .010 & $<.001$ & $1 \%$ \\
\hline \multicolumn{7}{|l|}{ Simple indirect associations } \\
\hline Marginalization $\rightarrow \mathrm{IH} \rightarrow$ Soc Loneliness & .030 & .082 & .050 & .116 & $<.001$ & $12 \%$ \\
\hline Marginalization $\rightarrow$ Stigma Preocc $\rightarrow$ Soc Loneliness & -.019 & -.053 & -.125 & .013 & .125 & $-8 \%$ \\
\hline Marginalization $\rightarrow$ Concealment $\rightarrow$ Soc Loneliness & .015 & .042 & .021 & .062 & $<.001$ & $6 \%$ \\
\hline Marginalization $\rightarrow$ Soc Anxiety $\rightarrow$ Soc Loneliness & .004 & .010 & .002 & .020 & .013 & $1 \%$ \\
\hline Marginalization $\rightarrow$ Inhibition $\rightarrow$ Soc loneliness & .0003 & .001 & -.037 & .040 & .934 & $<1 \%$ \\
\hline
\end{tabular}

Stigma Preocc $=$ stigma preoccupation, $\mathrm{IH}=$ internalized homonegativity, Soc Anxiety $=$ social anxiety, Inhibition $=$ social inhibition, Soc Loneliness $=$ social loneliness. $95 \%$ confidence intervals are for unstandardized betas $(B)$. Relative magnitude, a suggested effect size measure, is calculated by dividing each unstandardized indirect association by the total unstandardized association between marginalization and social/emotional loneliness. Associations ordered by size. Percentages rounded

Table 5 Indirect associations between marginalization and emotional loneliness

\begin{tabular}{|c|c|c|c|c|c|c|}
\hline \multirow[t]{2}{*}{ Indirect association } & \multirow[t]{2}{*}{$\beta$} & \multirow[t]{2}{*}{$B$} & \multicolumn{2}{|l|}{$95 \% \mathrm{CI}$} & \multirow[t]{2}{*}{$p$} & \multirow{2}{*}{$\begin{array}{l}\text { Relative } \\
\text { magnitude }\end{array}$} \\
\hline & & & Lower & Upper & & \\
\hline \multicolumn{7}{|l|}{ Serial indirect associations } \\
\hline Marginalization $\rightarrow$ Stigma Preocc $\rightarrow$ Soc Anxiety $\rightarrow$ Emo Loneliness & .049 & .128 & .106 & .152 & $<.001$ & $15 \%$ \\
\hline Marginalization $\rightarrow$ Stigma Preocc $\rightarrow$ Inhibition $\rightarrow$ Emo Loneliness & .023 & .061 & .043 & .081 & $<.001$ & $7 \%$ \\
\hline Marginalization $\rightarrow$ Concealment $\rightarrow$ Inhibition $\rightarrow$ Emo Loneliness & .007 & .018 & .012 & .025 & $<.001$ & $2 \%$ \\
\hline Marginalization $\rightarrow$ Concealment $\rightarrow$ Soc Anxiety $\rightarrow$ Emo Loneliness & .002 & .006 & .002 & .010 & .005 & $1 \%$ \\
\hline Marginalization $\rightarrow \mathrm{IH} \rightarrow$ Soc Anxiety $\rightarrow$ Emo Loneliness & .006 & .016 & .010 & .023 & $<.001$ & $2 \%$ \\
\hline Marginalization $\rightarrow \mathrm{IH} \rightarrow$ Inhibition $\rightarrow$ Emo Loneliness & .005 & .013 & .005 & .022 & .002 & $2 \%$ \\
\hline \multicolumn{7}{|l|}{ Simple indirect associations } \\
\hline Marginalization $\rightarrow \mathrm{IH} \rightarrow$ Emo Loneliness & .045 & .117 & .087 & .149 & $<.001$ & $14 \%$ \\
\hline Marginalization $\rightarrow$ Stigma Preocc $\rightarrow$ Emo Loneliness & -.020 & -.053 & -.117 & .009 & .100 & $-6 \%$ \\
\hline Marginalization $\rightarrow$ Soc Anxiety $\rightarrow$ Emo Loneliness & .010 & .027 & .005 & .049 & .019 & $3 \%$ \\
\hline Marginalization $\rightarrow$ Concealment $\rightarrow$ Emo Loneliness & .002 & .004 & -.015 & .022 & .663 & $<1 \%$ \\
\hline Marginalization $\rightarrow$ Inhibition $\rightarrow$ Emo Loneliness & .0003 & .001 & -.028 & .031 & .931 & $<1 \%$ \\
\hline
\end{tabular}

Stigma Preocc = stigma preoccupation, $\mathrm{IH}=$ internalized homonegativity, Soc Anxiety $=$ social anxiety, Inhibition $=$ social inhibition, Emo Loneliness $=$ emotional loneliness. $95 \%$ confidence intervals are for unstandardized betas $(B)$. Relative magnitude, a suggested effect size measure, is calculated by dividing each indirect association by the total association between marginalization and social/emotional loneliness. Associations ordered by size. Percentages rounded

role of concealment may have been muted because it is not necessarily negative for everyone. While some who conceal their orientation might become very self-conscious and constantly fear discovery (Pachankis, 2007), others may find that it has less impact on social anxiety because they are able to successfully avoid detection and, thus, marginalization (e.g., gender-conforming gay men). For its part, internalized homonegativity relates more to feelings and attitudes about the self rather than specific fear of evaluation by others.

We also found small direct associations between internalized homonegativity and both forms of loneliness, as well as between concealment and social loneliness. This is not surprising; internalized beliefs that non-heterosexual 
Table 6 Simple slopes as a function of differing levels of community involvement

\begin{tabular}{|c|c|c|c|c|c|c|}
\hline \multirow[t]{2}{*}{ Relationship } & \multirow{2}{*}{$\begin{array}{l}\text { Level of community } \\
\text { involvement }\end{array}$} & \multirow[t]{2}{*}{$\beta$} & \multirow[t]{2}{*}{$B$} & \multicolumn{2}{|l|}{$95 \% \mathrm{CI}$} & \multirow[t]{2}{*}{$p$} \\
\hline & & & & Lower & Upper & \\
\hline Marginalization $\rightarrow$ Internalized homonegativity & $\begin{array}{l}\text { Low } \\
\text { Average } \\
\text { High }\end{array}$ & $\begin{array}{l}.400 \\
.335 \\
.270\end{array}$ & $\begin{array}{l}.314 \\
.263 \\
.212\end{array}$ & $\begin{array}{l}.278 \\
.237 \\
.181\end{array}$ & $\begin{array}{l}.356 \\
.289 \\
.242\end{array}$ & $\begin{array}{l}<.001 \\
<.001 \\
<.001\end{array}$ \\
\hline Marginalization $\rightarrow$ Concealment & $\begin{array}{l}\text { Low } \\
\text { Average } \\
\text { High }\end{array}$ & $\begin{array}{l}.261 \\
.231 \\
.201\end{array}$ & $\begin{array}{l}2.586 \\
2.288 \\
1.990\end{array}$ & $\begin{array}{l}2.123 \\
1.989 \\
1.633\end{array}$ & $\begin{array}{l}3.064 \\
2.605 \\
2.345\end{array}$ & $\begin{array}{l}<.001 \\
<.001 \\
<.001\end{array}$ \\
\hline Marginalization $\rightarrow$ Stigma preoccupation & $\begin{array}{l}\text { Low } \\
\text { Average } \\
\text { High }\end{array}$ & $\begin{array}{l}.591 \\
.557 \\
.523\end{array}$ & $\begin{array}{l}3.088 \\
2.909 \\
2.731\end{array}$ & $\begin{array}{l}2.872 \\
2.742 \\
2.514\end{array}$ & $\begin{array}{l}3.310 \\
3.070 \\
2.928\end{array}$ & $\begin{array}{l}<.001 \\
<.001 \\
<.001\end{array}$ \\
\hline Concealment $\rightarrow$ Social anxiety & $\begin{array}{l}\text { Low } \\
\text { Average } \\
\text { High }\end{array}$ & $\begin{array}{l}.010 \\
.044 \\
.075\end{array}$ & $\begin{array}{l}.004 \\
.017 \\
.029\end{array}$ & $\begin{array}{r}-.013 \\
.006 \\
.011\end{array}$ & $\begin{array}{l}.021 \\
.027 \\
.049\end{array}$ & $\begin{array}{l}.687 \\
.002 \\
.002\end{array}$ \\
\hline Stigma Preoccupation $\rightarrow$ Social anxiety & $\begin{array}{l}\text { Low } \\
\text { Average } \\
\text { High }\end{array}$ & $\begin{array}{l}.449 \\
.366 \\
.284\end{array}$ & $\begin{array}{l}.327 \\
.267 \\
.207\end{array}$ & $\begin{array}{l}.264 \\
.238 \\
.127\end{array}$ & $\begin{array}{l}.405 \\
.295 \\
.273\end{array}$ & $\begin{array}{l}<.001 \\
<.001 \\
<.001\end{array}$ \\
\hline Social Inhibition $\rightarrow$ Social loneliness & $\begin{array}{l}\text { Low } \\
\text { Average } \\
\text { High }\end{array}$ & $\begin{array}{l}.392 \\
.347 \\
.301\end{array}$ & $\begin{array}{l}.309 \\
.273 \\
.237\end{array}$ & $\begin{array}{l}.272 \\
.251 \\
.198\end{array}$ & $\begin{array}{l}.347 \\
.295 \\
.276\end{array}$ & $\begin{array}{l}<.001 \\
<.001 \\
<.001\end{array}$ \\
\hline
\end{tabular}

High $=$ one standard deviation above the mean in community involvement. Average $=$ mean level of community involvement. Low $=$ one standard deviation below the mean in community involvement. $95 \%$ confidence intervals are for unstandardized betas $(B)$

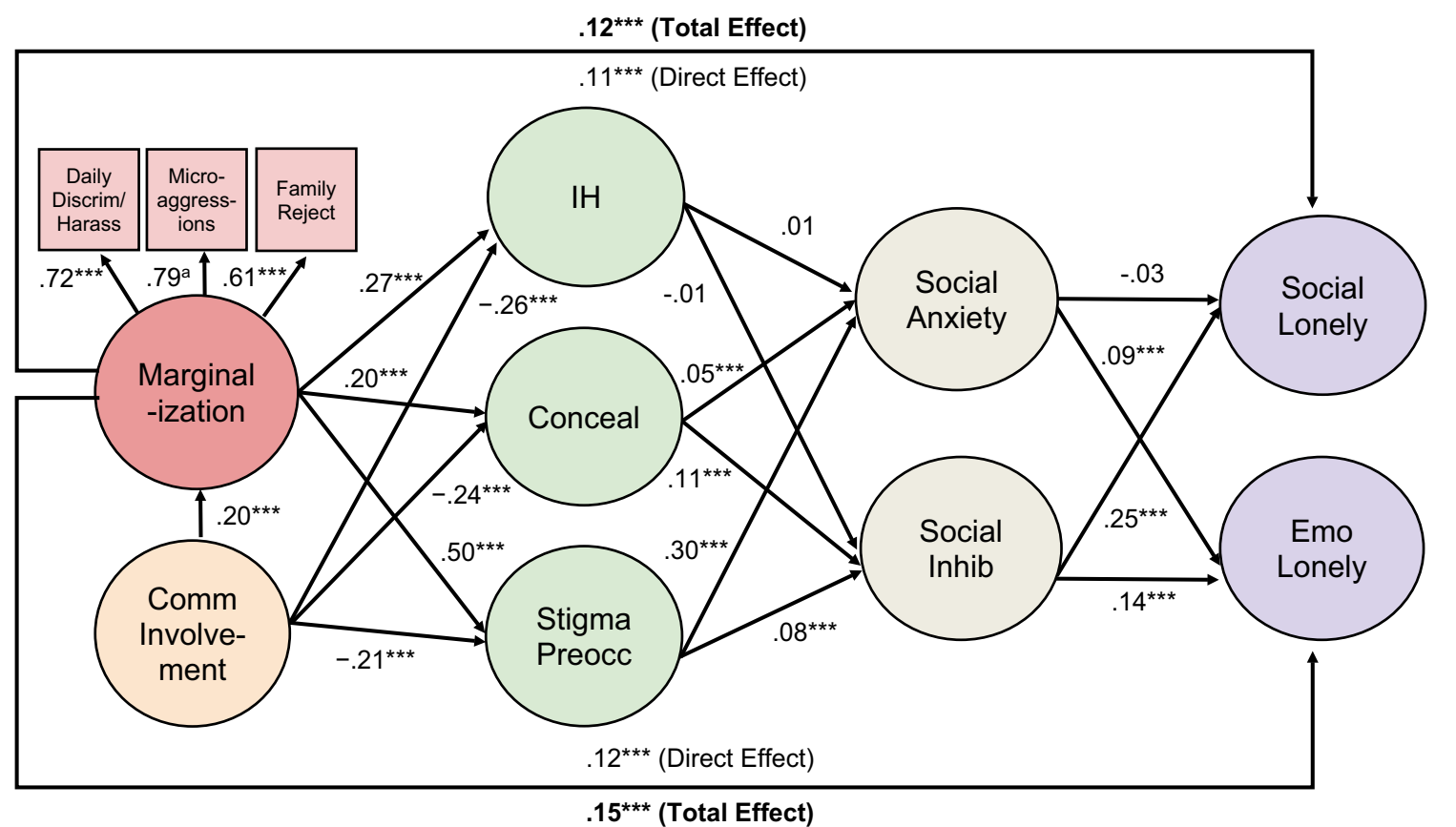

Fig. 3 Structural equation model linking marginalization and loneliness, adjusted for dispositional negative affectivity. Notes: Daily Dis$\mathrm{crim} /$ Harass $=$ everyday discrimination/harassment, Family Reject $=$ family rejection, Comm Involvement = community involvement, $\mathrm{IH}$ $=$ internalized homonegativity, Conceal $=$ concealment, Stigma Preocc $=$ stigma preoccupation, Social Inhib $=$ social inhibition, Social Lonely $=$ social loneliness, Emo Lonely $=$ emotional loneliness. For ease of presentation, direct associations between community involvement/proximal stress and both forms of loneliness are not shown, nor are direct associations between marginalization/community involve- ment and social anxiety/inhibition. The following correlated residuals (essentially factor correlations) are also not shown: internalized homonegativity and concealment $(r=.36, p<.001)$, internalized homonegativity and stigma preoccupation $(r=.49, p<.001)$, concealment and stigma preoccupation $(r=.38, p<.001)$, social anxiety and social inhibition $(r=.17, p<.001)$, and social and emotional loneliness $(r=.72, p<.001)$. All values are standardized regression coefficients. ${ }^{\text {a }}$ Strongest path fixed to 1.0 for statistical identification, thus $p$-value cannot be computed. $* * * p<.001, * * p<.01$ 
relationships are inferior or dysfunctional may reduce trust, commitment, and intimacy; and may increase relationship conflict and dissatisfaction (Cao et al., 2017; Downs, 2012; Doyle \& Molix, 2015; Frost \& Meyer, 2009). These beliefs might also foster unrealistically high relationship standards (Downs, 2012). For its part, concealment can contribute to social loneliness by increasing real and perceived distance from others and curtailing one's social network.

In contrast to most of the positive associations we found between minority stress and loneliness, there were some negative direct associations between stigma preoccupation and both forms of loneliness, which produced corresponding negative indirect associations between marginalization and loneliness. Although these associations were quite small and not statistically significant, they raise the possibility of countervailing relationships between marginalization and loneliness which should be explored in future studies. On one hand, marginalization could lead to loneliness if it increases social anxiety and inhibition to the point of interfering with relationships, as suggested by our model. On the other hand, marginalization might reduce loneliness to an extent by motivating some stigma-preoccupied individuals who are not anxious/inhibited to associate with people who are especially accepting and supportive.

Turning to relations between social anxiety, inhibition, and loneliness, is it perhaps unsurprising that inhibition was more strongly associated with social versus emotional loneliness. The former pertains to a broader social network, whereas the latter pertains to feelings of intimacy and attachment. Inhibited people may have trouble building a broad social network, especially in urban gay areas that cater to extroverts. It is also notable that social anxiety had a much stronger relationship with emotional versus social loneliness. Social anxiety relates to fears about social rejection; while these fears can apply in all situations, they may be more salient and consequential in the context of close rather than distant relationships (e.g., dating). This may be especially so for sexual minorities, for whom a history of rejection may have kindled fears about approval, trust, intimacy, and fidelity (Cao et al., 2017; Downs, 2012; Doyle \& Molix, 2016; Frost \& Meyer, 2009; Hobbes, 2017). Another reason for the strong relation between social anxiety and emotional loneliness is that they both share variance with negative affectivity (discussed below).

Overall, the total associations between marginalization and loneliness were moderate, based on empirically derived guidelines for interpreting effect sizes in social psychology (Lovakov $\&$ Agadullina, 2021). This is unsurprising given the multitude of reasons people may feel lonely (de Jong Gierveld et al., 2018; Elmer, 2018; Lim et al., 2020). Countervailing relationships between minority stress and loneliness, as suggested above, may also have limited the effect sizes. In addition, our sample reflected diverse experiences in 85 countries. While we controlled for broad geographic region, we did not control for specific country of residence. Associations in our model may be modest in some countries but stronger in others, which we will explore in another study using these same data. Finally, even moderate associations between minority stress and loneliness can have a serious impact, as loneliness is a well-known risk factor for morbidity and early mortality, especially when chronic (Cacioppo \& Cacioppo, 2014; Holt-Lunstad et al., 2015). Of particular concern, some respondents reported very high levels of minority stress, so they may be quite lonely and thus at even greater risk for health problems.

Indirect associations were also small in absolute value, although this is expected when using multiple serial mediators (Walters, 2019). Nonetheless, these associations suggest some of the theoretically and clinically relevant mechanisms by which minority stress may be related to loneliness. It is also important to note that while specific indirect associations may be small on their own, their combined effects can be meaningful, especially if they accumulate and compound over time, or if they impact large numbers of people (Götz et al., 2021).

In total, about $40 \%$ of the total relationship between marginalization loneliness was indirect. This could mean there are other unmeasured factors that play a role in the link between marginalization and loneliness (e.g., rumination, emotional dysregulation; Preece et al., 2021). Alternatively, it could mean that most of the relationship between marginalization and loneliness is, in fact, direct (e.g., marginalization directly leads to feeling different, misunderstood, or estranged, even in the absence of internalized homonegativity, concealment, stigma preoccupation, or social anxiety/ inhibition).

Loneliness itself could also contribute to marginalization; for example, those who are friendless or who have traits associated with loneliness (e.g., shyness, low self-esteem, passivity) may be targeted for harassment and bullying (Acquah et al., 2016; Pavri, 2015). Loneliness can also increase social withdrawal, self-focus, irritability, hostility, and other aversive behaviors and emotions that may elicit rejection by others (Cacioppo \& Hawkley, 2009; Cacioppo et al., 2017; Mund \& Neyer, 2016, 2019; Qualter et al., 2015; Segel-Karpas \& Ayalon, 2020; Spithoven et al., 2017; van Winkel et al., 2017). In this sense, marginalization and loneliness are likely mutually reinforcing; future studies using longitudinal data should examine this possibility. 


\section{Is LGBTQ Community Involvement Protective?}

Our study also examined the specific role of LGBTQ community involvement. Three findings are notable. First, there was a modest but positive association between community involvement and marginalization, in line with previous studies (Bissonette \& Syzmanski, 2019; Chan \& Mak, 2021; Foster-Gimbel et al., 2018; Kuyper et al., 2016; RamirezValles et al., 2005; Velez \& Moradi, 2016). One reason may be that those who are involved in the community are more open about their sexual orientation, which may increase their risk of marginalization (Bissonette \& Syzmanski, 2019; LeBeau \& Jellison, 2009). This is consistent with studies finding a positive association between outness and marginalization (e.g., Brewster et al., 2013; Cook et al., 2013; Timmins et al., 2020). Community involvement might also remind a person of their stigmatized status or contribute to a stronger sexual minority identity (LeBeau \& Jellison, 2009; Vaughan \& Waehler, 2010); this might increase perceptions and identification of marginalization (RamirezValles et al., 2005). Of course, the relationship between community involvement and marginalization may work in the other direction, too: those who experience or perceive marginalization in the first place may be more likely to join the LGBTQ community (e.g., to find support or advocate for LGBTQ rights; Chan \& Mak, 2021).

Although community involvement may confer risk for marginalization, our results are also consistent with the suggestion that it can protect against the negative consequences of marginalization, both by reducing the amount of proximal stress, inhibition, and loneliness, as well as buffering the links between these factors and marginalization. (Meyer, 2003). Notably, involvement was negatively associated with both forms of loneliness, with nearly half of this relationship being indirect via negative associations with proximal stress and social inhibition. While this suggests that community involvement plays a protective role, it is also possible that those who are more out and comfortable with their sexuality in the first place — as well as less inhibited—are more likely to get involved in the LGBTQ community.

We also found that the associations between marginalization and proximal stress were somewhat weaker among those who were more community-involved, as were associations between stigma preoccupation and social anxiety, and between social inhibition and social loneliness. Sexual minority peers can provide support to reduce the emotional impact of marginalization; a safe environment that reduces the need for self-monitoring and impression management; encouragement to resist or adaptively reappraise stigma and internalized homonegativity; and positive examples of successful relationships to counter self-defeating beliefs that same-sex relationships are inherently dysfunctional
(Cox et al., 2010; Meyer, 2003; Velez \& Moradi, 2016; Westefeld et al., 2001). Community involvement may also increase personal control and self-efficacy (Chan \& Mak, 2021; Heath \& Mulligan, 2008; van Lisdonk \& Kuyper, 2015; Wernick et al., 2014); this may reduce passivity and promote an active approach to relationships (e.g., managing social anxiety, meeting new people, resolving conflicts; Newall et al., 2014).

All of these advantages could help to reduce loneliness. So, too, could the more basic functions of LGBTQ community involvement-providing opportunities for socializing and meeting new friends and partners-which likely contributed to the direct associations we observed between community involvement and loneliness. In contrast to our hypotheses, however, community involvement did not appear to moderate the direct associations between marginalization and loneliness. These direct associations may be due partly to a sense of feeling different, misunderstood, or estranged from people outside the LGBTQ community; if so, perhaps community involvement is limited in its ability to reduce these feelings.

While valuable in many respects, community involvement may not benefit everyone to the same extent. First, some people are involved in the community but do not feel close to anyone, hence community involvement does not really protect them from loneliness. Indeed, what matters more in terms of loneliness is the perceived quality of relationships and feeling connected, not merely the presence of others (Hawkley et al., 2008). Second, very high levels of community involvement may take a toll for some people in terms of time, energy, and vicarious exposure to marginalization (Bissonette \& Syzmanski, 2019; Kulick et al., 2017). Third, the benefits of community involvement may be counterbalanced by various intra-minority stressors within the community itself. Examples include political conflicts, conformity, racism, bi-negativity, status-seeking, cliquishness, competitiveness, and a focus on youth, appearance, and sex, especially among younger gay men in urban centers and on social media/dating/ sex apps (Aggarwal \& Gerrets, 2014; Hammack et al., 2021; Heath \& Mulligan, 2008; Hobbes, 2017; LeBeau \& Jellison, 2009; Lehavot et al., 2009; Mereish et al., 2017; O'Byrne et al., 2014; Pachankis et al., 2020; Parmenter et al., 2020). The countervailing impact of these intra-minority stressors, which we intend to explore in another paper using these same data, may explain why the associations we observed between community involvement and loneliness were fairly small, as were interactions. The last finding of note was that for those higher in community involvement, there were slightly stronger associations between concealment and social anxiety. For people active in the LGBTQ community but not necessarily out to others, their fear of detection may be higher, thus increasing social anxiety in other areas of their life. 


\section{Is Dispositional Negative Affectivity a Confound?}

In light of criticism that associations between self-reported marginalization and mental health may be confounded by trait negative affectivity (NA; Bailey, 2020; Lilienfeld, 2017), we controlled for it in our study. After doing so, we found that our model still fit the data well, but total associations between marginalization and loneliness dropped by half. This ruled out the possibility that associations were mostly spurious, but confounding was still conceivable. At the same time, this procedure may have amounted to "over-control": to the extent that trait NA is caused by actual cumulative experiences of marginalization, controlling for it likely removed some of the variance intrinsic to marginalization and thus underestimated the true relationship between marginalization and loneliness (Lilienfeld, 2017). Similarly, we may have removed the variance in NA caused by proximal stress, anxiety/inhibition, and loneliness, as well as shared variance due to conceptual overlap between these variables. This likely contributed to the large declines in indirect associations. Importantly, we found similar reductions in associations when using frequency-only measures of marginalization that excluded subjective distress evaluations. If confounding were a serious issue, we should have seen more substantial reductions when using these measures, but we did not. Granted, even frequencyonly measures can be influenced by NA (e.g., misinterpreting ambiguous events as discrimination), but unlikely to the same extent. We also found no substantial reduction in associations between marginalization and proximal stress, which we would expect if NA were a major confound.

\section{Practical Implications}

Overall, our findings underscore the continuing need to reduce marginalization of sexual minorities. This would likely reduce loneliness, as well as the negative health impact associated with both minority stress (Flentje et al., 2020; Meyer, 2003) and loneliness (Cacioppo \& Cacioppo, 2014; Holt-Lunstad et al., 2015). Our findings also suggest possible interventions at the individual level. Clinicians might show clients how minority stress contributes to social anxiety, inhibition, and loneliness. This could help reframe their struggles as a natural response to marginalization rather than an inherent character defect (Velez \& Moradi, 2016). Clinicians could also show clients how negative affectivity may compound their perception of, and reaction to, minority stress. Skills could be taught to cope with minority stress, social anxiety, and inhibition, like identifying positive aspects of one's sexual orientation; checking automatic, yet possibly incorrect assumptions about innocuous or ambiguous social situations; improving emotion regulation in response to marginalization; minimizing avoidance; enhancing assertiveness and communication of needs and emotions; tempering unrealistic relationship standards; and reducing self-focus (Chaudoir et al., 2017; Downs, 2012; Feinstein, 2020; Hart et al., 2020; LeBeau, 2020; Smith et al., 2017).

These interventions are especially relevant to loneliness, which can exacerbate negative affectivity, hypervigilance, social anxiety, withdrawal, passivity, self-focus, negative social appraisals, and hostility (Cacioppo \& Hawkley, 2009; Cacioppo et al., 2013, 2017; Lim et al., 2016; Mund \& Johnson, 2021; Mund \& Neyer, 2019; Qualter et al., 2015; SegelKarpas \& Ayalon, 2020; Spithoven et al., 2017; van Winkel et al., 2017). Indeed, loneliness interventions showing the most promise are those which address maladaptive social cognition (Masi et al., 2011). Of course, care should be taken not to inadvertently pathologize the reactions to minority stress and loneliness. While they can be counterproductive if disproportionate or inflexible (e.g., expecting rejection even in neutral or welcoming situations), they ultimately begin as self-protective mechanisms that are adaptive in some situations (e.g., accurately anticipating or guarding against rejection or victimization in environments known to be hostile to sexual minorities).

Based on our findings, it would seem fruitful to encourage clients to develop stronger relationships with the LGBTQ community, so long as these relationships are healthy and supportive. This may even benefit those who are not particularly outgoing; indeed, the association between inhibition and social loneliness was lower for those who were more involved in the community. This is likely because inhibited people can still find a satisfying social network in the LGBTQ community by engaging in activities that do not involve large groups (e.g., being a member of a small support group). Of course, to the extent that minority stress, social anxiety, inhibition, and loneliness may be impeding relationships, these factors should be addressed beforehand; notably, some research finds that community involvement may have diminishing returns for people high in internalized homonegativity (Salfas et al., 2019). For service providers working with groups, they should also remember that loneliness can spread between people by distorting social cognition and reducing prosocial behavior (Cacioppo et al., 2009; Lieberz et al., 2021; Simon $\&$ Walker, 2018). These dynamics should be addressed proactively so that loneliness does not threaten the cohesion of groups and their ability to provide support.

For those experiencing minority stress within the community (e.g., racism, ageism), it may be useful to help them find additional or alternate sources of support and companionship. Indeed, some sexual minorities find that a mixed social network is healthier for them than relying exclusively on the LGBTQ community (Holt, 2011). This may be especially true for people who feel that their sexuality is not a central part of their identity.

Finally, clinicians should not underestimate the importance of basic health practices that are implicated in minority stress, social cognition, and loneliness. Sleep is a prime example. 
Longitudinal studies suggest not only that loneliness contributes to poor sleep-perhaps by increasing hypervigilance for social threat-but poor sleep also contributes to loneliness, perhaps by distorting social cognition, increasing emotional reactivity, and motivating social withdrawal (Hom et al., 2020). Given the impact of minority stress, it is not surprising that sexual minorities have more sleep problems compared to others (Patterson \& Potter, 2019); helping them improve sleep could buffer the links between minority stress and loneliness.

\section{Limitations, Strengths, and Future Directions}

Our findings should be interpreted in light of several limitations. First, the prevalence of minority stress-especially everyday discrimination/harassment, family rejection, and internalized homonegativity - was quite low. It is possible that those with higher levels of minority stress chose not to participate in our study. Moreover, social media ads were targeted to individuals who had divulged their sexual orientation (or interests related to sexual orientation), which may have biased the sample toward those who are more out/comfortable with their sexual orientation. Indeed, only about $30 \%$ of respondents indicated that they actively conceal their sexual orientation from others half of the time or more. Although low levels of marginalization and internalized homonegativity are not uncommon in many studies (e.g., Everett et al., 2009; Mereish \& Poteat, 2015; Mohr \& Kendra, 2011; van Lisdonk \& Kuyper, 2015; Velez \& Moradi, 2016), restricted range of responses may have underestimated some associations. Other variables did not exhibit restricted range.

Our data were based on self-report. In addition to the possible confounding role of general negative affectivity, responses were subject to social desirability and retrospective recall bias. Respondents may have under-reported minority stress and loneliness to counter perceptions that sexual minorities are inherently troubled. Conversely, some may have over-reported minority stress to underscore disparities between LGBTQ people and others. Although we focused on marginalization in the past twelve months, even this timeframe is subject to recall bias. Therefore, it would be useful to test our hypotheses using ecological momentary assessments and daily diary studies. It would also be useful to compare associations of loneliness with past-year versus lifetime marginalization (Ejlskov et al., 2020; Lyons et al., 2021).

All scales were administered in English. To minimize comprehension problems, we showed ads to social media users who had indicated that they understood English. Although internal consistency for scale responses was similar across countries and races/ethnicities-suggesting that items were understood in a similar manner-it is inevitable that non-native English speakers had greater difficulty understanding some questions. Moreover, in English-dominant countries, those without English proficiency may be of lower socioeconomic status (e.g., recent immigrants) and thus underrepresented in our survey. Conversely, bilingual respondents in countries where English is not dominant may be of higher SES (e.g., more educated), and thus less representative of the general LGBTQ population. SES is especially relevant to minority stress: not only are lower-SES sexual minorities more likely to be marginalized, they may also be more isolated from the mainstream LGBTQ community and thus more vulnerable to the negative impact of marginalization (McGarrity, 2014). That said, the median score on our income comfort scale was 4 (on a scale of 1-7) and responses were fairly normally distributed, with each level of income comfort well-represented. This suggests there were enough low-SES respondents in our sample. Nevertheless, our model should be compared across SES groups.

Our study had sizeable drop-out (45\%), apparently due to survey length. Although this rate is similar to that of other large online studies of sexuality and minority stress (e.g., Community-Based Research Centre, 2017; Meyer et al., 2020; Reimers, 2007), it may have biased our sample. Those who persevered may be unique in terms of minority stress exposure/perception, personality, motivation for participating (e.g., promotion of LGBTQ rights), cognitive ability, and health. Completion was higher among those who were older, White, queer, and pan/polysexual. In addition to being more conscientious, it is possible that older participants were more motivated to finish due to their greater involvement and interest in the LGBTQ community. They were also less likely to complete on a mobile device, resulting in fewer technical problems (e.g., trouble displaying items or pausing and resuming the survey). Similar reasons likely applied to queer and pan/polysexual individuals, who were more involved in the community and, with the exception of queer respondents, were also younger. White respondents likely experienced fewer language problems and were also younger and more likely to complete on a mobile device. It should be noted that the drop-out rate may have been inflated to some extent by users who began on one device and then started over on another (e.g., people who had technical problems on a mobile and switched to desktop). Their responses would appear to come from two different people, with the first set appearing to come from a non-completer. Unfortunately, it was not possible to determine how many of these respondents there were.

Finally, although SEM represents relationships as causal, our data were cross-sectional, and SEM by itself cannot prove causality. Our hypothetical model was consistent with our data, but alternate models proposing different causal mechanisms could also be a good fit to our data (e.g., models in which loneliness is hypothesized to increase social anxiety or perceptions of marginalization) (Kline, 2016). Although past research supports prospective links between some of our variables (e.g., Hatzenbuehler et al., 2008; Jackson et al., 2019; Pachankis \& Bernstein, 2012), additional longitudinal studies are needed to disentangle causal mechanisms. Indeed, temporal relationships 
proposed by our model are likely more complicated than in the usual formulations of minority stress theory, and may be bidirectional. For example, there is evidence that proximal stress can precede perceived marginalization (e.g., Douglass \& Conlin, 2020). Experimental studies could also be instructive (e.g., manipulating loneliness to see how it affects perceptions of minority stress, especially in ambiguous social situations).

Social media yielded a large, diverse sample from 85 countries. Minority stress studies have typically focused on single countries, usually in North America, Europe, and Australia. By contrast, many of our respondents were from countries that have received less attention, like South Africa and New Zealand, and one-third were from nonWestern regions. This allowed us to capture a wide range of experiences with minority stress, given the substantial cross-national variation in attitudes toward sexual minorities (e.g., European Union Agency for Fundamental Rights, 2020). Notably, even after controlling for broad geographic region, our models were still robust, with many mediumsize associations between minority stress, social anxiety/ inhibition, and loneliness. This suggests that minority stress uniquely contributes to mental health problems and loneliness, independent of one's location. These results are consistent with an international study of gay and bisexual men, which found that minority stress theory is a sound crosscultural model for understanding life satisfaction (Sattler \& Lemke, 2019). To extend our findings, it would be fruitful to compare our model by specific countries. It would also be useful to compare it by ethnoracial background, not simply with respect to respondents' self-identity, but also their perception of whether they are an ethnoracial minority in their country and whether others perceive them that way. Our single ethnoracial question did not permit this nuanced analysis. Comparisons by gender, sexual orientation, and age would also be informative.

Our study extends minority stress theory and the psychological mediation framework beyond commonly studied mental health and behavioral outcomes (e.g., depression, general anxiety, substance use) and into more interpersonal domains like loneliness. We also examined basic psychological processes that might underlie the relationship between minority stress and loneliness, and we considered both overt and subtle marginalization. We also examined the possible confounding role of dispositional negative affectivity, which many self-report studies overlook.

In contrast to research focusing mostly on the negative impact of minority stress, we also addressed a protective factor: involvement in the LGBTQ community. Thanks to social media, we reached people with widely varying levels of community involvement. This differs from many other studies, which have recruited people from LGBTQ venues and support organizations-people who are often highly involved in the community. This can be a source of bias because these individuals may have unique characteristics and higher rates of actual or perceived marginalization (Bissonette \& Syzmanski, 2019; Kuyper et al., 2016; Meyer \& Wilson, 2009; Pachankis et al., 2020).

Moving forward, studies should examine other types of marginalization like vicarious discrimination, additional proximal stress factors like difficulty developing a positive sexual identity, and other basic psychological factors like rumination and emotional dysregulation (e.g., Dyar et al., 2018; Sarno et al., 2020; Timmins et al., 2020). Finally, personality traits should be given more attention. Although we examined general negative affectivity, we did so only as a control variable. While this helped rule out the possibility that results were largely spurious, it did not permit an examination of negative affectivity as a precursor, mediator, or moderator in our model (Spector et al., 2000). Doing so would further extend minority stress theory and elucidate the specific mechanisms by which minority stress may lead to the development and reinforcement of loneliness.

Acknowledgements The authors express their gratitude to everyone who participated in this study. The authors also thank the handling editor, two anonymous reviewers, and Tawnya Boudier, Sarah Canham, Kiffer Card, Nina Conkova, Ted Hayes, Gian Hernandez, Randolph Hubach, Heather Campbell Pope, Valerie Spicer, Janelle Thompson, and Dale Quiring for helpful observations.

Funding This research was funded by a doctoral fellowship from the Social Sciences and Humanities Research Council of Canada, awarded to Eddy Elmer.

Data Availability Available by request from the first author.

\section{Declarations}

Conflict of interest The authors declared that they have no conflict of interest.

Ethics Approval Approval was obtained from the Research Ethics Review Committee, Faculty of Social Sciences, Vrije Universiteit Amsterdam. The procedures used in this study adhere to the tenets of the Declaration of Helsinki.

Informed Consent Informed consent was obtained from all individual participants included in the study.

Open Access This article is licensed under a Creative Commons Attribution 4.0 International License, which permits use, sharing, adaptation, distribution and reproduction in any medium or format, as long as you give appropriate credit to the original author(s) and the source, provide a link to the Creative Commons licence, and indicate if changes were made. The images or other third party material in this article are included in the article's Creative Commons licence, unless indicated otherwise in a credit line to the material. If material is not included in the article's Creative Commons licence and your intended use is not permitted by statutory regulation or exceeds the permitted use, you will need to obtain permission directly from the copyright holder. To view a copy of this licence, visit http://creativecommons.org/licenses/by/4.0/. 


\section{References}

AARP Foundation. (2018). Loneliness and social connections: A national survey of adults 45 and older. Washington, DC. https:// doi.org/10.26419/res.00246.001

Acquah, E. O., Topalli, P., Wilson, M. L., Junttila, N., \& Niemi, P. M. (2016). Adolescent loneliness and social anxiety as predictors of bullying victimisation. International Journal of Adolescence and Youth, 21(3), 320-331. https://doi.org/10.1080/02673843.2015.1083449

Aggarwal, S., \& Gerrets, R. (2014). Exploring a Dutch paradox: An ethnographic investigation of gay men's mental health. Culture, Health \& Sexuality, 16(2), 105-119. https://doi.org/10.1080/ 13691058.2013.841290

Aguinis, H., Gottfredson, R. K., \& Joo, H. (2013). Best-practice recommendations for defining, identifying, and handling outliers. Organizational Research Methods, 16(2), 270-301. https://doi. org/10.1177/1094428112470848

Allen, V. C., Jr., Lachance, C., Rios-Ellis, B., \& Kaphingst, K. A. (2011). Issues in the assessment of "race" among Latinos: Implications for research and policy. Hispanic Journal of Behavioral Sciences, 33(4), 411-424. https://doi.org/10.1177/0739986311422880

Angus Reid Institute. (2019). A portrait of social isolation and loneliness in Canada. https://angusreid.org/social-isolation-lonel iness-canada/

Araiza, A. M., Freitas, A. L., \& Klein, D. N. (2020). Social-experience and temperamental predictors of rejection sensitivity: A prospective study. Social Psychological and Personality Science, 11(6), 733-742. https://doi.org/10.1177/1948550619878422

Arbuckle, J. L. (2017). AMOS 25.0 user's guide. IBM SPSS.

Asendorpf, J. B. (1993). Social inhibition: A general developmental perspective. In H. C. Traue \& J. W. Pennebaker (Eds.), Emotion, inhibition, and health (pp. 80-99). Hogrefe \& Huber Publishers.

Badal, V. D., Graham, S. A., Depp, C. A., Shinkawa, K., Yamada, Y., Palinkas, L. A., Kim, H. C., Jeste, D. V., \& Lee, E. E. (2021). Prediction of loneliness in older adults using natural language processing: Exploring sex differences in speech. American Journal of Geriatric Psychiatry, 29(8), 853-866. https://doi.org/10. 1016/j.jagp.2020.09.009

Bailey, J. M. (2020). The minority stress model deserves reconsideration, not just extension [Commentary]. Archives of Sexual Behavior, 49(7), 2265-2268. https://doi.org/10.1007/s10508-019-01606-9

Balsam, K. F., Beadnell, B., \& Molina, Y. (2013). The Daily Heterosexist Experiences Questionnaire. Measurement and Evaluation in Counseling and Development, 46(1), 3-25. https://doi.org/ $10.1177 / 0748175612449743$

Baumeister, R. F., \& Leary, M. R. (1995). The need to belong: Desire for interpersonal attachments as a fundamental human motivation. Psychological Bulletin, 117(3), 497-529. https://doi.org/ 10.1037/0033-2909.117.3.497

Bereznai, S. (2006). Gay and single...forever? 10 things every gay guy looking for love (and not finding it) needs to know. Da Capo Lifelong Books.

Bergvik, S., Sørlie, T., Wynn, R., \& Sexton, H. (2010). Psychometric properties of the type D scale (DS14) in Norwegian cardiac patients. Scandinavian Journal of Psychology, 51(4), 334-340. https://doi.org/10.1111/j.1467-9450.2009.00793.x

Bissonette, D., \& Syzmanski, D. M. (2019). Minority stress and LGBQ college students' depression: Roles of peer group and involvement. Psychology of Sexual Orientation and Gender Diversity, 6(3), 308-317. https://doi.org/10.1037/sgd0000332

Blum, A. A. (2018, October 14). Are most gay men lonely? Advocate. https://www.advocate.com/love-and-sex/2018/10/14/ are-most-gay-men-lonely

Brewster, M. E., Moradi, B., DeBlaere, C., \& Velez, B. L. (2013). Navigating the borderlands: The roles of minority stressors, bicultural self-efficacy, and cognitive flexibility in the mental health of bisexual individuals. Journal of Counseling Psychology, 60(4), 543-556. https://doi.org/10.1037/a0033224

Brief, A. P., Burke, M. J., George, J. M., Robinson, B. S., \& Webster, J. (1988). Should negative affectivity remain an unmeasured variable in the study of job stress? Journal of Applied Psychology, 73(2), 193-198. https://doi.org/10.1037/0021-9010.73.2.193

Brown, T. A. (2015). Confirmatory factor analysis for applied research (2nd ed.). The Guilford Press.

Browne, M. W., \& Cudeck, R. (1993). Alternative ways of assessing model fit. In K. A. Bollen \& J. S. Long (Eds.), Testing structural equation models (pp. 136-162). Sage.

Byrne, B. M. (2010). Structural equation modeling with AMOS: Basic concepts, applications, and programming (2nd ed.). Routledge Taylor \& Francis.

Cacioppo, J. T., \& Cacioppo, S. (2014). Social relationships and health: The toxic effects of perceived social isolation. Social and Personality Psychology Compass, 8(2), 58-72. https://doi.org/10. 1111/spc3.12087

Cacioppo, J. T., Chen, H.-Y., \& Cacioppo, S. (2017). Reciprocal influences between loneliness and self-centeredness: A cross-lagged panel analysis in a population-based sample of African American, Hispanic and Caucasian adults. Personality and Social Psychology Bulletin, 43(8), 1125-1135. https://doi.org/10.1177/01461 67217705120

Cacioppo, J. T., Fowler, J. H., \& Christakis, N. A. (2009). Alone in the crowd: The structure and spread of loneliness in a large social network. Journal of Personality and Social Psychology, 97(6), 977-991. https://doi.org/10.1037/a0016076

Cacioppo, J. T., \& Hawkley, L. C. (2009). Perceived social isolation and cognition. Trends in Cognitive Sciences, 13(10), 447-454. https:// doi.org/10.1016/j.tics.2009.06.005

Cacioppo, J. T., Hawkley, L. C., \& Correll, J. (2013). Perceived social isolation within personal and evolutionary timescales. In N. C. DeWall (Ed.), The Oxford handbook of social exclusion (pp. 179-196). Oxford University Press.

Cacioppo, J. T., \& Patrick, B. (2008). Loneliness: Human nature and the need for social connection. W.W. Norton \& Company.

Cao, H., Zhou, N., Fine, M., Liang, Y., Li, J., \& Mills-Koonce, W. R. (2017). Sexual minority stress and same-sex relationship wellbeing: A meta-analysis of research prior to the U.S. nationwide legalization of same-sex marriage. Journal of Marriage and the Family, 79(5), 1258-1277. https://doi.org/10.1111/jomf.12415

Carleton, R. N., Collimore, K., \& Asmundson, G. J. G. (2007). Social anxiety and fear of negative evaluation: Construct validity of the BFNE-II. Journal of Anxiety Disorders, 21(1), 131-141. https://doi.org/10.1016/j.janxdis.2006.03.010

Carleton, R. N., McCreary, D. R., Norton, P. J., \& Asmundson, G. J. G. (2006). Brief Fear of Negative Evaluation Scale-Revised. Depression and Anxiety, 23(5), 297-303. https://doi.org/10. 1002/da.20142

Chan, R., \& Mak, W. (2021). Resistance as a form of resilience in sexual and gender minorities: Differential moderating roles of collective action on the discrimination-depression relationship among sexual minority men and women. Social Science \& Medicine. https://doi.org/10.1016/j.socscimed.2021.114056

Chaudoir, S. R., Wang, K., \& Pachankis, J. E. (2017). What reduces sexual minority stress? A review of the intervention "toolkit." Journal of Social Issues, 73(3), 586-617. https://doi.org/10. 1111/josi.12233

Choi, A. Y., Merrill, C. R. S., \& Israel, T. (2017). Factor structure of the Internalized Homonegativity Inventory (IHNI). Psychology of Sexual Orientation and Gender Diversity, 4(4), 491-498. https://doi.org/10.1037/sgd0000245

Coffman, D. L., \& MacCallum, R. C. (2005). Using parcels to convert path analysis models into latent variable models. Multivariate 
Behavioral Research, 40(2), 235-259. https://doi.org/10.1207/ s15327906mbr4002_4

Cohen, J. (1988). Statistical power analysis for the behavioral sciences (2nd ed.). Lawrence Erlbaum Associates.

Cohen, J. M., Blasey, C., Barr Taylor, C., Weiss, B. J., \& Newman, M. G. (2016). Anxiety and related disorders and concealment in sexual minority young adults. Behavior Therapy, 47(1), 91-101. https://doi.org/10.1016/j.beth.2015.09.006

Community-Based Research Centre (2017). Gay generations: Life course and gay men's health. Findings from the National Sex Now Survey. https://www.cbrc.net/sex_now_2015_montreal_ toronto_vancouver

Cook, S. H., Sandfort, T. G., Nel, J. A., \& Rich, E. P. (2013). Exploring the relationship between gender nonconformity and mental health among black South African gay and bisexual men. Archives of Sexual Behavior, 42(3), 327-330. https://doi.org/ 10.1007/s10508-013-0087-z

Cox, N., Vanden Berghe, W., Dewaele, A., \& Vincke, J. (2010). Acculturation strategies and mental health in gay, lesbian, and bisexual youth. Journal of Youth and Adolescence, 39(10), 1199-1210. https://doi.org/10.1007/s10964-009-9435-7

Croll, P. R., \& Gerteis, J. (2019). Race as an open field: Exploring identity beyond fixed choices. Sociology of Race and Ethnicity, 5(1), 55-69. https://doi.org/10.1177/2332649217748425

de Jong Gierveld, J. (1987). Developing and testing a model of loneliness. Journal of Personality and Social Psychology, 53(1), 119-128. https://doi.org/10.1037/0022-3514.53.1.119

de Jong Giervleld, J., \& Kamphuis, F. (1985). The development of a Rasch-type loneliness scale. Applied Psychological Measurement, 9(3), 289-299. https://doi.org/10.1177/0146621685 00900307

de Jong Gierveld, J., \& van Tilburg, T. G. (2010). The de Jong Gierveld short scales for social and emotional loneliness: Tested on data from seven countries in the UN Generations and Gender Surveys. European Journal of Ageing, 7(2), 121-130. https://doi.org/10.1007/s10433-010-0144-6

de Jong Gierveld, J., \& van Tilburg, T. G. (2021). Manual of the loneliness scale (Rev. ed.). Vrije Universiteit Amsterdam, Department of social research methodology. https://home.fsw.vu.nl/tg.van. tilburg/manual_loneliness_scale_1999.html

de Jong Gierveld, J., van Tilburg, T. G., \& Dykstra, P. A. (2018). New ways of theorizing and conducting research in the field of loneliness and social isolation. In A. Vagelisti \& D. Perlman (Eds.), The Cambridge handbook of personal relationships (2nd ed., pp. 391-404). Cambridge University Press.

de Moor, E. L., Denollet, J., \& Laceulle, O. M. (2018). Social inhibition, sense of belonging and vulnerability to internalizing problems. Journal of Affective Disorders, 225(1), 207-213. https://doi.org/ 10.1016/j.jad.2017.08.034

de Oliveira, J. M., Lopes, D., Costa, C. G., \& Nogeuira, C. (2012). Lesbian, gay and bisexual identity scale (LGBIS): Construct validation, sensitivity analyses and psychometric properties. Spanish Journal of Psychology, 15(1), 334-347. https://doi.org/10.5209/ rev_SJOP.2012.v15.n1.37340

Denollet, J. (2005). DS14: Standard assessment of negative affectivity, social inhibition, and type D personality. Psychosomatic Medicine, 67(1), 89-97. https://doi.org/10.1097/01.psy.0000149256. 81953.49

Dodwell, R. (2017). Not here. A queer anthology of loneliness. Pilot Press.

Douglass, R. P., \& Conlin, S. E. (2020). Minority stress among LGB people: Investigating relations among distal and proximal stressors. Current Psychology. https://doi.org/10.1007/ s12144-020-00885-Z

Downs, A. (2012). The velvet rage: Overcoming the pain of growing up gay in a straight man's world (2nd ed., rev.). Da Capo Lifelong Books.
Doyle, D. M., \& Molix, L. (2015). Social stigma and sexual minorities' romantic relationship functioning: A meta-analytic review. Personality and Social Psychology Bulletin, 41(10), 1363-1381. https://doi.org/10.1177/0146167215594592

Doyle, D. M., \& Molix, L. (2016). Disparities in social health by sexual orientation and the etiologic role of self-reported discrimination. Archives of Sexual Behavior, 45(6), 1317-1327. https://doi.org/ 10.1007/s10508-015-0639-5

Dyar, C., Feinstein, B. A., Eaton, N. R., \& London, B. (2018). The mediating roles of rejection sensitivity and proximal stress in the association between discrimination and internalizing symptoms among sexual minority women. Archives of Sexual Behavior, 47(1), 205-218. https://doi.org/10.1007/s10508-016-0869-1

Dyar, C., Sarno, E. L., Newcomb, M. E., \& Whitton, S. W. (2020). Longitudinal associations between minority stress, internalizing symptoms, and substance use among sexual and gender minority individuals assigned female at birth. Journal of Consulting and Clinical Psychology, 88(5), 389-401. https://doi.org/10.1037/ cсp0000487

Ejlskov, L., Bøggild, H., Kuh, D., \& Stafford, M. (2020). Social relationship adversities throughout the lifecourse and risk of loneliness in later life. Ageing \& Society, 40(8), 1718-1734. https://doi.org/ 10.1017/S0144686X19000345

Elmer, E. M. (2018). Social isolation and loneliness among seniors in Vancouver: Strategies for reduction and prevention. City of Vancouver Seniors' Advisory Committee. https://www.seniorslon eliness.ca

Eres, R., Postolovski, N., Thielking, M., \& Lim, M. H. (2021). Loneliness, mental health, and social health indicators in LGBTQIA+ Australians. American Journal of Orthopsychiatry, 91(3), 358366. https://doi.org/10.1037/ort0000531

European Union Agency for Fundamental Rights. (2014). European Union Lesbian, Gay, Bisexual and Transgender Survey. Luxembourg, LU. https://fra.europa.eu/node/11550

European Union Agency for Fundamental Rights. (2020). A long way to go for LGBTI equality. Luxembourg, LU. https://fra.europa.eu/ en/publication/2020/eu-lgbti-survey-results

Everett, B. G., Steele, S. M., Matthews, A. K., \& Hughes, T. L. (2019), Gender, race, and minority stress among sexual minority women: An intersectional approach. Archives of Sexual Behavior, 48(5), 1505-1517. https://doi.org/10.1007/s10508-019-1421-x

Fairchild, A. J., \& MacKinnon, D. P. (2009). A general model for testing mediation and moderation effects. Prevention Science, 10(2), 87-99. https://doi.org/10.1007/s11121-008-0109-6

Feinstein, B. A. (2020). The rejection sensitivity model as a framework for understanding sexual minority mental health. Archives of Sexual Behavior, 49(7), 2247-2258. https://doi.org/10.1007/ s10508-019-1428-3

Feinstein, B. A., Goldfried, M. R., \& Davila, J. (2012). The relationship between experiences of discrimination and mental health among lesbians and gay men: An examination of internalized homonegativity and rejection sensitivity as potential mechanisms. Journal of Consulting and Clinical Psychology, 80(5), 917-927. https:// doi.org/10.1037/a0029425

Flentje, A., Heck, N. C., Brennan, J. M., \& Meyer, I. H. (2020). The relationship between minority stress and biological outcomes: A systematic review. Journal of Behavioral Medicine, 43(5), 673-694. https://doi.org/10.1007/s10865-019-00120-6

Fokkema, T., \& Kuyper, L. (2009). The relation between social embeddedness and loneliness among older lesbian, gay, and bisexual adults in the Netherlands. Archives of Sexual Behavior, 38(2), 264-275. https://doi.org/10.1007/s10508-007-9252-6

Foster-Gimbel, O., Doyle, D. M., \& Engeln, R. (2020). The gay community involvement index: An exploratory factor analysis and initial validation of a new measure of Gay Community Involvement. 
Archives of Sexual Behavior, 49(1), 233-247. https://doi.org/10. 1007/s10508-018-1271-y

Frost, D. M., \& Meyer, I. H. (2009). Internalized homophobia and relationship quality among lesbians, gay men, and bisexuals. Journal of Counseling Psychology, 56(1), 97-109. https://doi.org/10. 1037/a0012844

Gest, S. D. (1997). Behavioral inhibition: Stability and associations with adaptation from childhood to early adulthood. Journal of Personality and Social Psychology, 72(2), 467-475. https://doi. org/10.1037/0022-3514.72.2.467

Götz, F. M., Gosling, S. D., \& Rentfrow, P. J. (2021). Small effects: The indispensable foundation for a cumulative psychological science. Perspectives on Psychological Science. https://doi.org/10.1177/ 1745691620984483

Grande, G., Romppel, M., Glaesmer, H., Petrowski, K., \& HerrmannLingen, C. (2010). The Type-D Scale (DS14): Norms and prevalence of type-D personality in a population-based representative sample in Germany. Personality and Individual Differences, 48(8), 935-939. https://doi.org/10.1016/j.paid.2010.02.026

Hammack, P. L., Grecco, B., Wilson, B. D. M., \& Meyer, I. H. (2021). "White, tall, top, masculine, muscular": Narratives of intracommunity stigma in young sexual minority men's experience on mobile apps. Archives of Sexual Behavior. https://doi.org/10. 1007/s10508-021-02144-z

Hart, T. A., Noor, S. W., Vernon, J., Antony, M. M., Gardner, S., \& O'Cleirigh, C. (2020). Integrated cognitive-behavioral therapy for social anxiety and HIV/STI prevention for gay and bisexual men: A pilot intervention trial. Behavior Therapy, 51(3), 503-517. https://doi.org/10.1016/j.beth.2019.09.001

Hatzenbuehler, M. L. (2009). How does sexual minority stigma "get under the skin"? A psychological mediation framework. Psychological Bulletin, 135(5), 707-730. https://doi.org/10.1037/a0016441

Hatzenbuehler, M. L., Nolen-Hoeksema, S., \& Erickson, S. (2008). Minority stress predictors of HIV risk behavior, substance use, and depressive symptoms: Results from a prospective study of bereaved gay men. Health Psychology, 27(4), 455-462. https:// doi.org/10.1037/0278-6133.27.4.455

Hawkley, L. C., Browne, M. W., \& Cacioppo, J. T. (2005). How can I connect with thee? Let me count the ways. Psychological Science, 16(10), 798-804. https://doi.org/10.1111/j.1467-9280.2005.01617.x

Hawkley, L. C., Hughes, M. E., Waite, L. J., Masi, C. M., Thisted, R. A., \& Cacioppo, J. T. (2008). From social structural factors to perceptions of relationship quality and loneliness: The Chicago Health, Aging, and Social Relations Study. Journals of Gerontology Series B: Psychological Sciences and Social Sciences, 63(6), S375-S384. https://doi.org/10.1093/geronb/63.6.s375

Hayes, A. F., \& Preacher, K. J. (2013). Conditional process modeling: Using structural equation modeling to examine contingent causal processes. In G. R. Hancock \& R. O. Mueller (Eds.), Structural equation modeling: A second course (pp. 219-266). Information Age Publishing.

Heath, M., \& Mulligan, E. (2008). 'Shiny happy same-sex attracted woman seeking same': How communities contribute to bisexual and lesbian women's well-being. Health Sociology Review, 17(3), 290-302. https://doi.org/10.5172/hesr.451.17.3.290

Hobbes, M. (2017, March 2). Together alone: The epidemic of gay loneliness. Huffington Post_-Highline. https://highline.huffington post.com/articles/en/gay-loneliness/

Holt, M. (2011). Gay men and ambivalence about 'gay community': From gay community attachment to personal communities. Culture, Health \& Sexuality, 13(8), 857-871. https://doi.org/10.1080/ 13691058.2011.581390

Holt-Lunstad, J., Smith, T. B., Baker, M., Harris, T., \& Stephenson, D. (2015). Loneliness and social isolation as risk factors for mortality: A meta-analytic review. Perspectives on Psychological Science, 10(2), 227-237. https://doi.org/10.1177/1745691614568352
Hom, M. A., Chu, C., Rogers, M. L., \& Joiner, T. E. (2020). A metaanalysis of the relationship between sleep problems and loneliness. Clinical Psychological Science, 8(5), 799-824. https://doi. org/10.1177/2167702620922969

Hsieh, N., \& Liu, H. (2021). Social relationships and loneliness in late adulthood: Disparities by sexual orientation. Journal of Marriage and Family, 83(1), 57-74. https://doi.org/10.1111/jomf.12681

Hu, L. T., \& Bentler, P. M. (1999). Cutoff criteria for fit indexes in covariance structure analysis: Conventional criteria versus new alternatives. Structural Equation Modeling, 6(1), 1-55. https:// doi.org/10.1080/10705519909540118

Jackson, D. L. (2003). Revisiting sample size and number of parameter estimates: Some support for the N:Q hypothesis. Structural Equation Modeling, 10(1), 128-141. https://doi.org/10.1207/ S15328007SEM1001_6

Jackson, S. E., Hackett, R. A., Grabovac, I., Smith, L., \& Steptoe, A. (2019). Perceived discrimination, health and wellbeing among middle-aged and older lesbian, gay and bisexual people: A prospective study. PLoS ONE, 14(5), e216497. https://doi.org/10. 1371/journal.pone.0216497

Jacobs, R. J., \& Kane, M. N. (2012). Correlates of loneliness in midlife and older gay men. Journal of Gay \& Lesbian Social Services, 24(1), 40-61. https://doi.org/10.1080/10538720.2012.643217

Jiang, D., Hou, Y., Chen, X., Wang, R., Fu, C., Li, B., Jin, L., Lee, T., \& Liu, X. (2019). Interpersonal sensitivity and loneliness among Chinese gay men: A cross-sectional survey. International Journal of Environmental Research and Public Health, 16(11), 2039. https://doi.org/10.3390/ijerph16112039

Kemer, G., Demirtaş, E. T., Pope, A. L., \& Ummak, E. (2017). Psychometric properties of the lesbian, gay and bisexual identity scale_-Turkish (LGBIS-TR). Journal of Homosexuality, 64(12), 1632-1649. https://doi.org/10.1080/00918369.2016.1249741

Kenny, D. A. (2011). Terminology and basics of SEM. http://david akenny.net $/ \mathrm{cm} /$ basics.htm

Kenny, D. A. (2012). Identification. http://davidakenny.net/cm/ident ify_formal.htm

Kim, H. J., \& Fredriksen-Goldsen, K. I. (2016). Living arrangement and loneliness among lesbian, gay, and bisexual older adults. The Gerontologist, 56(3), 548-558. https://doi.org/10.1093/geront/ gnu083

King, D. R., O’Rourke, N., \& DeLongis, A. (2014). Social media recruitment and online data collection: A beginner's guide and best practices for accessing low-prevalence and hard-to-reach populations. Canadian Psychology, 55(4), 240-249. https://doi. org/10.1037/a0038087

Kline, R. B. (2016). Principles and practice of structural equation modeling (4th ed.). The Guilford Press.

Knoble, N. B., \& Linville, D. (2010). Outness and relationship satisfaction in same-gender couples. Journal of Marital and Family Therapy, 38(2), 330-339. https://doi.org/10.1111/j.1752-0606. 2010.00206.x

Knowles, M. L., Lucas, G. M., Baumeister, R. F., \& Gardner, W. L. (2015). Choking under social pressure: Social monitoring among the lonely. Personality and Social Psychology Bulletin, 41(6), 805-821. https://doi.org/10.1177/0146167215580775

Kodama, S. (2021, February 13). Japan appoints 'minister of loneliness' to help people home alone. Nikkei Times. https://asia.nikkei.com/Spotlight/Coronavirus/Japan-appoints-minister-of-lonel iness-to-help-people-home-alone

Kulick, A., Wernick, L. J., Woodford, M. R., \& Renn, K. (2017). Heterosexism, depression, and campus engagement among LGBTQ college students: Intersectional differences and opportunities for healing. Journal of Homosexuality, 64(8), 1125-1141. https:// doi.org/10.1080/00918369.2016.1242333

Kuyper, L., \& Bos, H. (2016). Mostly heterosexual and lesbian/gay young adults: Differences in mental health and substance use 
and the role of minority stress. Journal of Sex Research, 53(7), 731-741. https://doi.org/10.1080/00224499.2015.1071310

Kuyper, L., Fernee, H., \& Keuzenkamp, S. (2016). A comparative analysis of a community and general sample of lesbian, gay, and bisexual individuals. Archives of Sexual Behavior, 45(3), 683693. https://doi.org/10.1007/s10508-014-0457-1

Kuyper, L., \& Fokkema, T. (2010). Loneliness among older lesbian, gay, and bisexual adults: The role of minority stress. Archives of Sexual Behavior, 39(5), 1171-1180. https://doi.org/10.1007/ s10508-009-9513-7

LeBeau, R. T. (2020). The rejection sensitivity framework's promise as a guiding force for the development of sexual and gender minority mental health interventions. Archives of Sexual Behavior, 49(7), 2275-2279. https://doi.org/10.1007/s10508-019-01613-w

LeBeau, R. T., \& Jellison, W. A. (2009). Why get involved? Exploring gay and bisexual men's experience of the gay community. Journal of Homosexuality, 56(1), 56-76. https://doi.org/10.1080/00918 360802551522

Lehavot, K., Balsam, K. F., \& Ibrahim-Wells, G. D. (2009). Redefining the American quilt: Definitions and experiences of community among ethnically diverse lesbian and bisexual women. Journal of Community Psychology, 37(4), 439-458. https://doi.org/10. 1002/jcop.20305

Lieberz, J., Shamay-Tsoory, S. G., Saporta, N., Esser, T., Kuskova, E., Stoffel-Wagner, B., Hurlemann, R., \& Scheele, D. (2021). Loneliness and the social brain: How perceived social isolation impairs human interactions. Advanced Science, 8(21), e2102076. https:// doi.org/10.1002/advs.202102076

Lilienfeld, S. O. (2017). Microaggressions: Strong claims, inadequate evidence. Perspectives on Psychological Science, 12(1), 138-169. https://doi.org/10.1177/1745691616659391

Lim, H. E., Lee, M.-S., Ko, Y.-H., Park, Y.-M., Joe, S.-H., Kim, Y.-K., Han, C., Lee, H.-Y., Pedersen, S. S., \& Denollet, J. (2011). Assessment of the type D personality construct in the Korean population: A validation study of the Korean DS14. Journal of Korean Medical Science, 26(1), 116-123. https://doi.org/10.3346/jkms. 2011.26.1.116

Lim, M. H., Eres, R., \& Vasan, S. (2020). Understanding loneliness in the twenty-first century: An update on correlates, risk factors, and potential solutions. Social Psychiatry and Psychiatric Epidemiology, 55(7), 793-810. https://doi.org/10.1007/ s00127-020-01889-7

Lim, M. H., Rodebaugh, T. L., Zyphur, M. J., \& Gleeson, J. F. M. (2016). Loneliness over time: The crucial role of social anxiety. Journal of Abnormal Psychology, 125(5), 620-630. https://doi. org/10.1037/abn0000162

Lin, G.-C., Wen, Z., Marsh, H. W., \& Lin, H.-Y. (2010). Structural equation models of latent interactions: Clarification of orthogonalizing and double-mean-centering strategies. Structural Equation Modeling, 17(3), 374-391. https://doi.org/10.1080/10705511.2010. 488999

Little, T. D., Cunningham, W. A., Shahar, G., \& Widaman, K. F. (2002). To parcel or not to parcel: Exploring the question, weighing the merits. Structural Equation Modeling, 9(2), 151-173. https://doi. org/10.1207/S15328007SEM0902_1

Littler, C., \& Joy, P. (2021). Queer considerations: Exploring the use of social media for research recruitment within LGBTQ communities. Research Ethics, 17(3), 267-274. https://doi.org/10.1177/ 17470161211003021

London, B., Downey, G., Bonica, C., \& Paltin, I. (2007). Social causes and consequences of rejection sensitivity. Journal of Research on Adolescence, 17(3), 481-506. https://doi.org/10.1111/j.15327795.2007.00531.x

Lovakov, A., \& Agadullina, E. R. (2021). Empirically derived guidelines for effect size interpretation in social psychology. European
Journal of Social Psychology, 51(3), 485-504. https://doi.org/ 10.1002/ejsp.2752

Lunn, M., Cui, W., Zack, M., Thompson, W., Blank, M., \& Yehia, B. (2017). Sociodemographic characteristics and health outcomes among lesbian, gay, and bisexual U.S. adults using healthy people 2020 leading health indicators. LGBT Health, 4(4), 283-294. https://doi.org/10.1089/lgbt.2016.0087

Lyons, A., Alba, B., Waling, A., Minichiello, V., Hughes, M., Barrett, C., Fredricksen-Goldsen, K., Edmonds, S., \& Blanchard, M. (2021). Recent versus lifetime experiences of discrimination and the mental and physical health of older lesbian women and gay men. Ageing \& Society, 41(5), 1072-1093. https://doi.org/10. 1017/S0144686X19001533

Mahon, C. P., Lombard-Vance, R., Kiernan, G., Pachankis, J. E., \& Gallagher, P. (2021). Social anxiety among sexual minority individuals: A systematic review. Psychology \& Sexuality. https://doi. org/10.1080/19419899.2021.1936140

Masi, C. M., Chen, H.-Y., Hawkley, L. C., \& Cacioppo, J. T. (2011). A meta-analysis of interventions to reduce loneliness. Personality and Social Psychology Review, 15(3), 219-266. https://doi.org/ $10.1177 / 1088868310377394$

Mayfield, W. (2001). The development of an internalized homonegativity inventory for gay men. Journal of Homosexuality, 41(2), 53-76. https://doi.org/10.1300/J082v41n02_04

McDonald, R. P., \& Ho, M.-H.R. (2002). Principles and practice in reporting structural equation analyses. Psychological Methods, 7(1), 64-82. https://doi.org/10.1037/1082-989X.7.1.64

McGarrity, L. A. (2014). Socioeconomic status as context for minority stress and health disparities among lesbian, gay, and bisexual individuals. Psychology of Sexual Orientation and Gender Diversity, 1(4), 383-397. https://doi.org/10.1037/sgd0000067

McNeish, D. (2018). Thanks coefficient alpha, we'll take it from here. Psychological Methods, 23(3), 412-433. https://doi.org/10.1037/ met0000144

Meidlinger, P. C., \& Hope, D. A. (2014). Differentiating disclosure and concealment in measurement of outness for sexual minorities: The Nebraska outness scale. Psychology of Sexual Orientation and Gender Diversity, 1(4), 489-497. https://doi.org/10.1037/ sgd0000080

Mereish, E. H., Katz-Wise, S. L., \& Woulfe, J. (2017). Bisexual-specific minority stressors, psychological distress, and suicidality in bisexual individuals: The mediating role of loneliness. Prevention Science, 18(6), 716-725. https://doi.org/10.1007/ s11121-017-0804-2

Mereish, E. H., \& Poteat, V. (2015). A relational model of sexual minority mental and physical health: The negative effects of shame on relationships, loneliness, and health. Journal of Counseling Psychology, 62(3), 425-437. https://doi.org/10.1037/cou0000088

MetLife Mature Market Institute. (2010). Still out, still aging. Westport, CT. https://www.asaging.org/sites/default/files/files/mmi-stillout-still-aging.pdf

Meyer, I. H. (1995). Minority stress and mental health in gay men. Journal of Health and Social Behavior, 36(1), 38-56. https://doi. org $/ 10.2307 / 2137286$

Meyer, I. H. (2003). Prejudice, social stress, and mental health in lesbian, gay, and bisexual populations: Conceptual issues and research evidence. Psychological Bulletin, 129(5), 674-697. https://doi.org/10.1037/0033-2909.129.5.674

Meyer, I. H., Marken, S., Russell, S. T., Frost, D. M., \& Wilson, B. (2020). An innovative approach to the design of a national probability sample of sexual minority adults. LGBT Health, 7(2), 101-108. https://doi.org/10.1089/lgbt.2019.0145

Meyer, I. H., \& Wilson, P. A. (2009). Sampling lesbian, gay, and bisexual populations. Journal of Counseling Psychology, 56(1), 23-31. https://doi.org/10.1037/a0014587 
Mohr, J. J., \& Kendra, M. S. (2011). Revision and extension of a multidimensional measure of sexual minority identity: The Lesbian, gay, and bisexual identity scale. Journal of Counseling Psychology, 58(2), 234-245. https://doi.org/10.1037/a0022858

Morrison, T. G., Bishop, C. J., Morrison, M. A., \& Parker-Taneo, K. (2016). A psychometric review of measures assessing discrimination against sexual minorities. Journal of Homosexuality, 63(8), 1086-1126. https://doi.org/10.1080/00918369.2015.1117903

Mund, M., \& Johnson, M. D. (2021). Lonely me, lonely you: Loneliness and the longitudinal course of relationship satisfaction. Journal of Happiness Studies, 22(2), 575-597. https://doi.org/10.1007/ s10902-020-00241-9

Mund, M., \& Neyer, F. J. (2016). The winding paths of the lonesome cowboy: Evidence for mutual influences between personality, subjective health, and loneliness. Journal of Personality, 84(5), 646-657. https://doi.org/10.1111/jopy.12188

Mund, M., \& Neyer, F. J. (2019). Loneliness effects on personality. International Journal of Behavioral Development, 43(2), 136146. https://doi.org/10.1177/0165025418800224

Nadal, K. L., Whitman, C. N., Davis, L. S., Erazo, T., \& Davidoff, K. C. (2016). Microaggressions toward lesbian, gay, bisexual, transgender, queer, and genderqueer people: A review of the literature. Journal of Sex Research, 53(4-5), 488-508. https://doi.org/10. 1080/00224499.2016.1142495

National Seniors Council of Canada. (2017). Wh's at risk and what can be done about it: A review of the literature on the social isolation of different groups of seniors. Government of Canada. https:// www.canada.ca/en/national-seniors-council/programs/publicatio ns-reports/2017/review-social-isolation-seniors.html

Newall, N. E. G., Chipperfield, J. G., \& Bailis, D. S. (2014). Predicting stability and change in loneliness in later life. Journal of Social and Personal Relationships, 31(3), 335-351. https://doi.org/10. 1177/0265407513494951

Newheiser, A.-K., \& Barreto, M. (2014). Hidden costs of hiding stigma: Ironic interpersonal consequences of concealing a stigmatized identity in social interactions. Journal of Experimental Social Psychology, 52, 58-70. https://doi.org/10.1016/j.jesp.2014.01. 002

Nicolaisen, M., \& Thorsen, K. (2014). Who are lonely? Loneliness in different age groups (18-81 years old) using two measures of loneliness. International Journal of Aging and Human Development, 78(3), 229-257. https://doi.org/10.2190/ag.78.3.b

Norona, J. C., \& Welsh, D. P. (2016). Rejection sensitivity and relationship satisfaction in dating relationships: The mediating role of differentiation of self. Couple and Family Psychology: Research and Practice, 5(2), 124-135. https://doi.org/10.1037/cfp0000056

O’Boyle, E., \& Williams, L. J. (2011). Decomposing model fit: Measurement vs. theory in organizational research using latent variables. Journal of Applied Psychology, 96(1), 1-12. https://doi. org/10.1037/a0020539 [Online calculator also available: https:// fgoeddeke.shinyapps.io/rmseap/]

O’Byrne, P., Bryan, A., Hendriks, A., Horvath, C., Bouchard, C., \& Etches, V. (2014). Social marginalization and internal exclusion: Gay men's understandings and experiences of community. The Canadian Journal of Nursing Research, 46(2), 57-79. https://doi. org/10.1177/084456211404600206

Pachankis, J. E. (2007). The psychological implications of concealing a stigma: A cognitive-affective-behavioral model. Psychological Bulletin, 133(2), 328-345. https://doi.org/10.1037/0033-2909. 133.2.328

Pachankis, J. E., \& Bernstein, L. B. (2012). An etiological model of anxiety in young gay men: From early stress to public self-consciousness. Psychology of Men \& Masculinities, 13(2), 107-122. https://doi.org/10.1037/a0024594

Pachankis, J. E., Clark, K. A., Burton, C. L., Hughto, J. M. W., Bränström, R., \& Keene, D. E. (2020). Sex, status, competition, and exclusion: Intraminority stress from within the gay community and gay and bisexual men's mental health. Journal of Personality and Social Psychology, 119(3), 713-740. https://doi.org/10. 1037/pspp0000282

Pachankis, J. E., Goldfried, M. R., \& Ramrattan, M. E. (2008). Extension of the rejection sensitivity construct to the interpersonal functioning of gay men. Journal of Consulting and Clinical Psychology, 76(2), 306-317. https://doi.org/10.1037/0022-006x. 76.2.306

Pachankis, J. E., Sullivan, T. J., Feinstein, B. A., \& Newcomb, M. E. (2018). Young adult gay and bisexual men's stigma experiences and mental health: An 8-year longitudinal study. Developmental Psychology, 54(7), 1381-1393. https://doi.org/10.1037/dev00 00518

Parent, M. C. (2013). Handling item-level missing data: Simpler is just as good. The Counseling Psychologist, 41(4), 568-600. https:// doi.org/10.1177/0011000012445176

Parmenter, J. G., Galliher, R. V., \& Maughan, D. A. (2020). LGBTQ+ emerging adults perceptions of discrimination and exclusion within the LGBTQ+ community. Psychology \& Sexuality, 12(4), 289-304. https://doi.org/10.1080/19419899.2020.1716056

Patterson, C. J., \& Potter, E. C. (2019). Sexual orientation and sleep difficulties: A review of research. Sleep Health, 5(3), 227-235. https://doi.org/10.1016/j.sleh.2019.02.004

Pavri, S. (2015). Loneliness: The cause or consequence of peer victimization in children and youth. The Open Psychology Journal, 8, 78-84. https://doi.org/10.2174/1874350101508010078

Pepping, C. A., Cronin, T. J., Halford, W. K., \& Lyons, A. (2019). Minority stress and same-sex relationship satisfaction: The role of concealment motivation. Family Process, 58(2), 496-508. https:// doi.org/10.1111/famp.12365

Preacher, K. J., \& Kelley, K. (2011). Effect size measures for mediation models: Quantitative strategies for communicating indirect effects. Psychological Methods, 16(2), 93-115. https://doi.org/ 10.1037/a0022658

Preece, D. A., Goldenberg, A., Becerra, R., Boyes, M., Hasking, P., \& Gross, J. J. (2021). Loneliness and emotion regulation. Personality and Individual Differences, 180, 110974. https://doi.org/10. 1016/j.paid.2021.110974

Qualter, P., Vanhalst, J., Harris, R., Van Roekel, E., Lodder, G., Bangee, M., Maes, M., \& Verhagen, M. (2015). Loneliness across the life span. Perspectives on Psychological Science, 10(2), 250-264. https://doi.org/10.1177/1745691615568999

Ramirez-Valles, J., Fergus, S., Reisen, C. A., Poppen, P. J., \& Zea, M. C. (2005). Confronting stigma: Community involvement and psychological well-being among HIV-positive Latino gay men. Hispanic Journal of Behavioral Sciences, 27(1), 101-119. https://doi.org/10.1177/0739986304270232

Reimers, S. (2007). The BBC Internet Study: General methodology. Archives of Sexual Behavior, 36(2), 147-161. https://doi.org/ 10.1007/s10508-006-9143-2

Roberts, L. M., \& Christens, B. D. (2021). Pathways to well-being among LGBT adults: Sociopolitical involvement, family support, outness, and community connectedness with race/ethnicity as a moderator. American Journal of Community Psychology, 67(3-4), 405-418. https://doi.org/10.1002/ajcp.12482

SAGE USA (Services \& Advocacy for Gay, Lesbian, Bisexual \& Transgender Elders) (2014). Out \& visible: The experiences and attitudes of lesbian, gay, bisexual and transgender older adults, ages 45-75. https://www.sageusa.org/resource-posts/out-visiblethe-experiences-and-attitudes-of-lesbian-gay-bisexual-and-trans gender-older-adults-ages-45-75-by-the-numbers-full-report/

Salfas, B., Rendina, H. J., \& Parsons, J. T. (2019). What is the role of the community? Examining minority stress processes among gay and bisexual men. Stigma and Health, 4(3), 300-309. https://doi. org/10.1037/sah0000143 
Sarno, E. L., Newcomb, M. E., \& Mustanski, B. (2020). Rumination longitudinally mediates the association of minority stress and depression in sexual and gender minority individuals. Journal of Abnormal Psychology, 129(4), 355-363. https://doi.org/10. 1037/abn0000508

Sattler, F. A., \& Lemke, R. (2019). Testing the cross-cultural robustness of the minority stress model in gay and bisexual men. Journal of Homosexuality, 66(2), 189-208. https://doi.org/10.1080/00918 369.2017.1400310

Schafer, J. L. (1999). Multiple imputation: A primer. Statistical Methods in Medical Research, 8(1), 3-15. https://doi.org/10.1177/09622 8029900800102

Schermelleh-Engel, K., Moosbrugger, H., \& Müller, H. (2003). Evaluating the fit of structural equation models: Tests of significance and descriptive goodness-of-fit measures. Methods of Psychological Research Online, 8(2), 23-74.

Schneider, F. R., Blanco, C., Antia, S. X., \& Liebowitz, M. R. (2002). The social anxiety spectrum. Psychiatric Clinics of North America, 25(4), 757-774. https://doi.org/10.1016/S0193-953X(02) 00018-7

Schrimshaw, E. W., Siegel, K., Downing, M. J., \& Parsons, J. T. (2013). Disclosure and concealment of sexual orientation and the mental health of non-gay-identified, behaviorally bisexual men. Journal of Consulting and Clinical Psychology, 81(1), 141-153. https:// doi.org/10.1037/a0031272

Segel-Karpas, D., \& Ayalon, L. (2020). Loneliness and hostility in older adults: A cross-lagged model. Psychology and Aging, 35(2), 169176. https://doi.org/10.1037/pag0000417

Shangani, S., Gamarel, K. E., Ogunbajo, A., Cai, J., \& Operario, D. (2020). Intersectional minority stress disparities among sexual minority adults in the USA: The role of race/ethnicity and socioeconomic status. Culture, Health \& Sexuality, 22(4), 398-412. https://doi.org/10.1080/13691058.2019.1604994

Simon, E. B., \& Walker, M. P. (2018). Sleep loss causes social withdrawal and loneliness. Nature Communications, 9(1), 3146. https://doi.org/10.1038/s41467-018-05377-0

Smith, N. G., Hart, T. A., Kidwai, A., Vernon, J., Blais, M., \& Adam, B. (2017). Results of a pilot study to ameliorate psychological and behavioral outcomes of minority stress among young gay and bisexual men. Behavior Therapy, 48(5), 664-677. https://doi.org/ 10.1016/j.beth.2017.03.005

Spector, P. E., Zapf, D., Chen, P. Y., \& Frese, M. (2000). Why negative affectivity should not be controlled in job stress research: Don't throw out the baby with the bath water. Journal of Organizational Behavior, 21(1), 79-95. https://doi.org/10.1002/(SICI) 1099-1379(200002)21:1\%3c79::AID-JOB964\%3e3.0.CO;2-G

Spithoven, A. W. M., Bijttebier, P., \& Goossens, L. (2017). It is all in their mind: A review on information processing bias in lonely individuals. Clinical Psychology Review, 58, 97-114. https://doi. org/10.1016/j.cpr.2017.10.003

Thompson, B., \& Melancon, J. G. (1996). Using item "testlets"/"parcels" in confirmatory factor analysis: An example using the PPSDQ-78 [Paper presentation]. Annual Meeting of the Mid-South Educational Research Association, Tuscaloosa, AL, USA. https://eric.ed.gov/?id=ED404349

Thornton, L., Batterham, P. J., Fassnacht, D. B., Kay-Lambkin, F., Calear, A. L., \& Hunt, S. (2016). Recruiting for health, medical or psychosocial research using facebook: Systematic review. Internet Interventions, 4(1), 72-81. https://doi.org/10.1016/j. invent.2016.02.001

Tiggemann, M., Martins, Y., \& Kirkbride, A. (2007). Oh to be lean and muscular: Body image ideals in gay and heterosexual men. Psychology of Men \& Masculinities, 8(1), 15-24. https://doi.org/ 10.1037/1524-9220.8.1.15

Timmins, L., Rimes, K. A., \& Rahman, Q. (2020). Minority stressors, rumination, and psychological distress in lesbian, gay, and bisexual individuals. Archives of Sexual Behavior, 49(2), 661680. https://doi.org/10.1007/s10508-019-01502-2

Tomarken, A. J., \& Waller, N. G. (2003). Potential problems with "well fitting" models. Journal of Abnormal Psychology, 112(4), 578598. https://doi.org/10.1037/0021-843X.112.4.578

Toomey, R. B., Ryan, C., Diaz, R. M., \& Russell, S. T. (2011). High school gay-straight alliances (GSAs) and young adult well-being: An examination of GSA presence, participation, and perceived effectiveness. Applied Developmental Science, 15(4), 175-185. https://doi.org/10.1080/10888691.2011.607378

United Kingdom Government. (2018). A connected society: A strategy for tackling loneliness. https://www.gov.uk/government/publi cations/a-connected-society-a-strategy-for-tackling-loneliness

Uysal-Bozkir, Ö., Fokkema, T., MacNeil-Vroomen, J. L., van Tilburg, T. G., \& de Rooij, S. E. (2017). Translation and validation of the De Jong Gierveld loneliness scale among older migrants living in the Netherlands. Journals of Gerontology Series B: Psychological Sciences \& Social Sciences, 72(1), 109-119. https://doi.org/10. 1093/geronb/gbv044

van Lisdonk, J., \& Kuyper, L. (2015). 55-plussers en seksuele oriëntatie: Ervaringen van lesbische, homoseksuele, biseksuele en heteroseksuele 55-plussers [People over 55 and sexual orientation: Experiences of lesbian, gay, bisexual and heterosexual adults over 55]. The Hague, NL: Netherlands Institute for Social Research. https://ww.researchgate.net/publication/290446775_55-plussers_ en_seksuele_orientatie_Ervaringen_van_lesbische_homoseksue le_biseksuele_en_heteroseksuele_55-plussers

van Tilburg, T. G., \& Fokkema, T. (2021). Stronger feelings of loneliness among Moroccan and Turkish older adults in the Netherlands: In search for an explanation. European Journal of Ageing, 22, 311-322. https://doi.org/10.1007/s10433-020-00562-x

van Tilburg, T. G., Havens, B., \& de Jong Gierveld, J. (2004). Loneliness among older adults in the Netherlands, Italy, and Canada: A multifaceted comparison. Canadian Journal of Aging, 23(2), 169-180. https://doi.org/10.1353/cja.2004.0026

van Winkel, M., Wichers, M., Collip, D., Jacobs, N., Derom, C., Thiery, E., Myin-Germeys, I., \& Peeters, F. (2017). Unraveling the role of loneliness in depression: The relationship between daily life experience and behavior. Psychiatry: Interpersonal and Biological Processes, 80(2), 104-11. https://doi.org/10.1080/00332747.2016.1256143

Vanhalst, J., Luyckx, K., Scholte, R. H., Engels, R. C. M. E., \& Goossens, L. (2013). Low self-esteem as a risk factor for loneliness in adolescence: Perceived — but not actual—social acceptance as an underlying mechanism. Journal of Abnormal Child Psychology, 41(7), 1067-1081. https://doi.org/10.1007/s10802-013-9751-y

Vaughan, M. D., \& Waehler, C. A. (2010). Coming out growth: Conceptualizing and measuring stress-related growth associated with coming out to others as a sexual minority. Journal of Adult Development, 17(2), 94-109. https://doi.org/10.1007/ s10804-009-9084-9

Velez, B. L., \& Moradi, B. (2016). A moderated mediation test of minority stress: The role of collective action. The Counseling Psychologist, 44(8), 1132-1157. https://doi.org/10.1177/00110 00016665467

Victor, C. R., Grenade, L., \& Boldy, D. (2005). Measuring loneliness in later life: A comparison of differing measures. Reviews in Clinical Gerontology, 15(1), 63-70. https://doi.org/10.1017/S095925980 5001723

Walters, G. D. (2019). Why are mediation effects so small? International Journal of Social Research Methodology, 22(2), 219-232. https://doi.org/10.1080/13645579.2018.1517232

Warren, R., Smith, R. E., \& Cybenko, A. K. (2011). Use of Mahalanobis distance for detecting outliers and outlier clusters in markedly non-normal data: A vehicular traffic example. Dayton, OH: SRA International Inc. https://ntrl.ntis.gov/NTRL/dashboard/searc hResults/titleDetail/ADA545834.xhtml 
Watson, D., \& Clark, L. A. (1984). Negative affectivity: The disposition to experience aversive emotional states. Psychological Bulletin, 96(3), 465-490. https://doi.org/10.1037/0033-2909.96.3.465

Watson, J., \& Nesdale, D. (2012). Rejection sensitivity, social withdrawal, and loneliness in young adults. Journal of Applied Social Psychology, 42(8), 1984-2005. https://doi.org/10.1111/j.15591816.2012.00927.x

Wegner, R., \& Wright, A. J. (2016). A psychometric evaluation of the Homonegative Microaggressions Scale. Journal of Gay \& Lesbian Mental Health, 20(4), 299-318. https://doi.org/10.1080/ 19359705.2016.1177627

Weiss, R. S. (1973). Loneliness: The experience of social and emotional isolation. MIT Press.

Wen, Z., \& Fan, X. (2015). Monotonicity of effect sizes: Questioning kappa-squared as mediation effect size measure. Psychological Methods, 20(2), 193-203. https://doi.org/10.1037/met0000029

Wernick, L. J., Kulick, A., \& Woodford, M. R. (2014). How theater within a transformative organizing framework cultivates individual and collective empowerment among LGBTQQ youth. Journal of Community Psychology, 42(7), 838-853. https://doi. org/10.1002/jcop. 21656

Westefeld, J. S., Maples, M. R., Buford, B., \& Taylor, C. (2001). Gay, lesbian, and bisexual college students: The relationship between sexual orientation and depression, loneliness, and suicide.
Journal of College Student Psychotherapy, 15(3), 71-82. https:// doi.org/10.1300/J035v15n03_06

Westland, J. C. (2010). Lower bounds on sample size in structural equation modeling. Electronic Commerce Research and Applications, 9(6), 476-487. https://doi.org/10.1016/j.elerap.2010.07.003 [Online calculator by Daniel Soper also available: https://www. danielsoper.com/statcalc]

Wright, A. J., \& Wegner, R. (2012). Homonegative microaggressions and their impact on LGB individuals: A measure validity study. Journal of LGBT Issues in Counseling, 6(1), 34-54. https://doi. org/10.1080/15538605.2012.648578

Zhou, J., Li, X., Tian, L., \& Huebner, E. S. (2020). Longitudinal association between low self-esteem and depression in early adolescents: The role of rejection sensitivity and loneliness. Psychology and Psychotherapy: Theory Research and Practice, 93(1), 54-71. https://doi.org/10.1111/papt.12207

Zimmer-Gembeck, M. J., Nesdale, D., Webb, H. J., Khatibi, M., \& Downey, G. (2016). A longitudinal rejection sensitivity model of depression and aggression: Unique roles of anxiety, anger, blame, withdrawal and retribution. Journal of Abnormal Child Psychology, 44(7), 1291-1307. https://doi.org/10.1007/s10802-016-0127-y

Publisher's Note Springer Nature remains neutral with regard to jurisdictional claims in published maps and institutional affiliations. 